\title{
A review of elastocaloric cooling: materials, cycles and system integrations
}

\author{
Suxin Qian ${ }^{\mathrm{a}}$, Yunlong Geng ${ }^{\mathrm{b}}$, Yi Wang ${ }^{\mathrm{b}}$, Jiazhen Ling ${ }^{\mathrm{a}}$, Yunho Hwang ${ }^{\mathrm{a}}$, Reinhard Radermacher ${ }^{\mathrm{a}}$, \\ Ichiro Takeuchi ${ }^{\mathrm{b}}$, Jun Cui ${ }^{\mathrm{c}}$ \\ ${ }^{a}$ Center for Environmental Energy Engineering, Department of Mechanical Engineering, \\ University of Maryland, 4164 Glenn L. Martin Hall Bldg., College Park, MD 20742, USA \\ ${ }^{b}$ Department of Material Science and Engineering, University of Maryland, 1242 Jeong H. Kim \\ Engineering Building, College Park, MD 20742, USA \\ ${ }^{\mathrm{c}}$ The Ames Laboratory and Department of Materials Science and Engineering, Iowa State \\ University. \\ *Corresponding Author \\ Tel: (+1) 301-405-5247, Fax: (+1) 301-405-2025, Email: yhhwang@umd.edu
}

\begin{abstract}
Elastocaloric cooling is a new alternative solid-state cooling technology undergoing early stage research and development. This study presents a comprehensive review of key issues related to achieving a successful elastocaloric cooling system. Fundamentals in elastocaloric materials are reviewed. The basic and advanced thermodynamic cycles are presented based on analogy from other solid-state cooling technologies. System integration issues are discussed to characterize the next generation elastocaloric cooling prototype. Knowledge acquired from the elastocaloric heat engines is provided as the basis for the design of cooling system configuration. Commercially available drivers enabling proper compression and tension are also presented. A few performance assessment indices are proposed and discussed as guidelines for design and evaluation of future elastocaloric cooling system. A brief summary of the up-to-date elastocaloric cooling prototypes is presented as well.
\end{abstract}


Keywords: shape memory alloys, not-in-kind cooling, nitinol, martensitic tranformation, thermoelastic, vapor compression, refrigeration, thermodynamics

\section{Nomenclature}

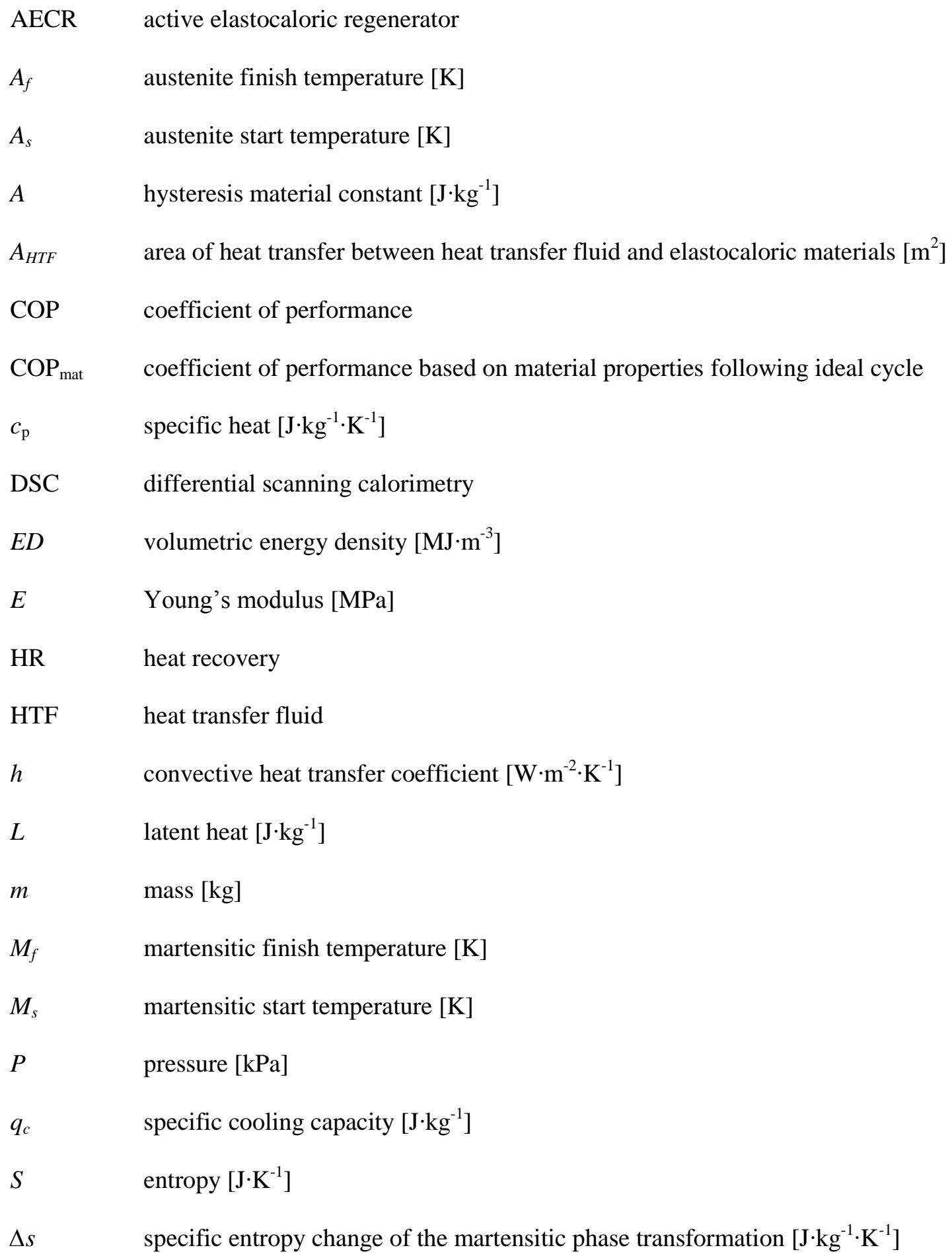


SMAs $\quad$ shape memory alloys

TMR thermal mass ratio between elastocaloric material and dead mass, Eq. (8) [-]

$T M \quad$ thermal mass $\left[\mathrm{J} \cdot \mathrm{K}^{-1}\right]$

$T \quad$ temperature $[\mathrm{K}]$

$T_{c} \quad$ cold side external fluid temperature of a heat pump system [K]

$T_{h} \quad$ hot side external fluid temperature of a heat pump system [K]

$T_{p c} \quad$ phase change temperature $[\mathrm{K}]$

$\Delta T_{\text {lift }} \quad$ system temperature lift $[\mathrm{K}]$

$\Delta T_{a d} \quad$ adiabatic temperature span of the material [K]

$V \quad$ volume $\left[\mathrm{m}^{3}\right]$

$\dot{V} \quad$ volumetric flow rate $\left[\mathrm{m}^{3} \cdot \mathrm{s}^{-1}\right]$

WR work recovery

$w+\quad$ specific loading energy $\left[\mathrm{J} \cdot \mathrm{kg}^{-1}\right]$

$w$ - $\quad$ specific unloading energy $\left[\mathrm{J}^{\mathrm{kg}} \mathrm{kg}^{-1}\right]$

$\alpha_{\mathrm{L}} \quad$ thermal expansion coefficient $\left[\mathrm{K}^{-1}\right]$

$\sigma_{\text {sat }} \quad$ saturation stress $[\mathrm{MPa}]$

$\sigma_{\mathrm{AM}} \quad$ austenite to martensite phase change saturation stress [MPa]

$\sigma_{\mathrm{MA}} \quad$ martensite to austenite phase change saturation stress [MPa]

$\sigma^{*} \quad$ logical stress, as described in Eq. (10) [-]

$\varepsilon \quad$ Strain

$\varepsilon_{\mathrm{M}} \quad$ martensite strain at stress free state

$\rho \quad$ density $\left[\mathrm{kg} \cdot \mathrm{m}^{-3}\right]$

$\gamma \quad$ non-dimensional latent heat $[-]$

$\Phi \quad$ uniformity index [-] 


\section{Introduction}

Elastocaloric cooling, also known as thermoelastic cooling, has been recognized as a promising alternative to the state-of-the-art vapor compression cooling systems (Goetlzer et al., 2014). It is based on the latent heat associated with the martensitic phase transformation process, which has been found in shape memory alloys (SMAs) when they are subjected to cyclic uniaxial loading and unloading stresses. Figure 1 visualizes the stress-induced phase transformation process. The SMA is initially fully austenite under the stress-free state at the application temperature. When the stress on the SMA exceeds the "saturation stress" of phase change, the austenite starts to transform into the martensite phase. During the phase transformation, entropy reduces and latent heat is released to the ambient. The reverse phase change from martensite to austenite takes place once the loading stress decreases below the "saturation stress" of phase change. The "saturation stress" of unloading may not be identical to that of loading due to hysteresis, as will be discussed in more details later. The entropy increases and the SMA absorbs heat from the ambient, which could be used for producing the cooling effect. This principle determines the cyclic operation nature of elastocaloric cooling system, which is the most important difference from vapor compression cooling. Another major difference from the vapor compression system is the requirement of a heat transfer fluid (HTF), since solid-state SMAs cannot flow like a conventional liquid or gaseous refrigerant.

Figure 2 shows the typical features of an elastocaloric cooling or heat pump system. The most important part is the elastocaloric materials, and therefore, an entire section of this paper focuses on the materials' research and development. Materials with different viable cycles are also discussed. The second feature is the loading/driving system requiring work input. Unlike those compressible gaseous refrigerants used in vapor compression systems undergoing more than $200 \%$ specific volume change, the solid-state phase change in elastocaloric material is usually corresponding to less than $10 \%$ strain, and as a result, requires much higher stress (pressure). To achieve the compression of solid, commercial linear drivers may be used and they are 
summarized in this paper. Heat transfer between the elastocaloric material and the HTF is important as well. The discussion of the third feature is based on a few proposed performance assessment indices. The system layout in Figure 2 consists of two beds that are filled with elastocaloric materials and has the heat recovery (HR) and work recovery (WR) features, as proposed by Qian et al. (2015b) and Schmidt et al. (2015). The HR precools the hot bed and preheats the cold bed simultaneously before unloading/loading process to reduce the parasitic heat loss caused by cyclic variation of temperatures of the elastocaloric materials and other parasitic supporting parts (Qian et al., 2015a). The active regenerator design (Tusek et al., 2015b) is another viable option to achieve simultaneous heat transfer and HR. To recover the mechanical work, WR requires a conjugated elastocaloric materials beds configuration in the system, as demonstrated by Figure 2. The two beds are both halfway pre-loaded in the beginning so that when one bed is $100 \%$ loaded reaching the maximum strain, the other one is fully unloaded back to zero strain. In this way, the unloading energy from one bed is automatically recovered by the loading process of another one. Auxiliary parts, such as pumps, fans and even cooling towers consume power as well. This auxiliary power consumption is not trivial in the system performance evaluation and should not be neglected.

\section{Elastocaloric cooling materials}

2.1 Thermodynamics of Elastocaloric Materials

SMAs have been used mainly for biomedical applications in the past due to their superior superelastic mechanical performance. Jani et al. (2014) carried out a comprehensive summary of various applications of SMAs.

The most important relation for elastocaloric materials from elastocaloric effect perspective is the Clausius-Clapeyron equation (Otsuka and Wayman, 1998), which correlates the constitutive relation of elastocaloric material with the latent heat of the phase transformation, as shown in Eq. (1). 
$\left(\frac{d \sigma}{d T}\right)_{s a t}=-\frac{\rho \Delta s}{\varepsilon_{M}}$

where the left hand side stands for the transformation stress and temperature ratio under equilibrium conditions, and right hand side is the ratio between the volumetric entropy change and the phase transformation strain.

However, it needs attention when using Eq. (1) because the loading and unloading processes of elastocaloric materials have a non-trivial hysteresis. If the hysteresis is not negligible, the corresponding saturation temperature/stress has to be given for Eq. (1). The hysteresis results from complicated interactions of many factors such as alloying, composition, heat treatment, cyclic operation and aging (Ortin and Delaey, 2002). Despite the various causes of the hysteresis, it measures the amount of energy dissipated during the cyclic operation. In other words, a minimum hysteresis is preferred from a thermal efficiency perspective. Less hysteresis is also desirable because it leads a longer fatigue life for elastocaloric materials (Cui et al., 2006, Eggeler et al., 2004). Figure 3 visualizes the hysteresis under two different driving modes and on a three dimensional phase diagram as well. Figure 3(a) shows the thermally driven cycle with hysteresis under the constant zero stress condition. The thermally driven cycle represents a heat engine cycle, which converts heat into strain variation (linear motion or vibration) and dissipates heat to a low temperature heat sink. Initially, the elastocaloric material starts below the martensitic finish temperature $\left(\mathrm{M}_{\mathrm{f}}\right)$ and is heated. It remains in the single martensite phase until reaching the austenite start temperature $\left(\mathrm{A}_{\mathrm{s}}\right)$. Phase transformation from martensite to austenite is initiated upon further heating until it reaches the austenite finish temperature $\left(\mathrm{A}_{\mathrm{f}}\right)$. The material remains in the austenite phase during the reverse cooling process until its temperature reaches the martensite start temperature $\left(\mathrm{M}_{\mathrm{s}}\right)$. By further cooling, it transforms from the austenite phase back to the martensite until it approaches $\mathrm{M}_{\mathrm{f}}$. In a thermally driven cycle, heat source at an excessively higher temperature level than $\mathrm{M}_{\mathrm{s}}$ is required for the martensite to transform into austenite, while heat sink at lower temperature level than $\mathrm{A}_{\mathrm{s}}$ is needed to achieve a reverse phase change. Ideally, 
all four temperatures should be equal if there is no hysteresis, such as the boiling temperature and condensation temperature under the constant pressure are identical in a vapor-liquid system. Figure 3(b) represents the hysteresis associated with a stress-driven cycle under the constant temperature condition, which is used for a cooling or heat pump system. The stress keeps increasing to the saturation stress $\sigma_{\mathrm{AM}}$ corresponding to $\mathrm{M}_{\mathrm{s}}$, when the material starts the phase transformation towards martensite. Since $A_{s}$ is greater than $M_{s}$, the reverse phase change saturation stress $\sigma_{\mathrm{MA}}$ is less than $\sigma_{\mathrm{AM}}$ under the same temperature.

Figure 3(c) shows the well-known linear relation between the phase transformation saturation stress and the temperature reported for various elastocaloric materials in the past (Bekker and Brinson, 1997, 1998; Liang and Rogers, 1990; Lu and Weng, 1997). The real shape of the saturation stress-temperature curve may not be strictly linear due to many other factors. The four intersection states on the temperature scale represents the four temperatures under the stress-free condition in Figure 3(a). The four curves divide the entire domain into five sub-areas, and therefore, can be used as a phase diagram. The term phase diagram here follows the traditional thermodynamics convention for a single species gas-liquid-solid system (Moran et al., 2011), which is different from the alloys community, where a phase diagram for elastocaloric materials mainly refers to the phase distribution when the alloy composition varies (Otsuka and Wayman, 1998; Otsuka and Ren, 2005; Recarte et al., 1999). Above the $\mathrm{M}_{\mathrm{f}}$ curve is the single phase martensite, and austenite single phase is located below the $\mathrm{A}_{\mathrm{f}}$ curve. Due to hysteresis, there are two regions where both phases exist in equilibrium, which are the area between the $M_{s}$ and $M_{f}$ and the area between $A_{s}$ and $A_{f}$. The region between the two start curves represents the metastable states.

Following the gas-liquid-solid convention, a stress-strain-temperature surface visualizes the combined relation of Figure 3(a), (b) and (c), as demonstrated in Figure 3(d). This approach has been demonstrated for a nickel-titanium binary alloy in literature (McNichols and Cory, 1987; Peyroux et al., 1998; Schiller, 2002). In Figure 3(d), martensite single phase surface is bounded 
by red lines, which is adjacent to the A-M two-phase surface. The M-A two-phase surface deviates from the A-M surface due to the hysteresis. Given the context of a vapor-liquid system, there is only a single two-phase surface since there is no hysteresis between boiling and condensation. The states in between the M-A and A-M two-phase surfaces are metastable, which means they will evolve to stable states upon any disturbance. Austenite is adjacent to the M-A two-phase surface, which is bounded by the green lines. The four stress-temperature curves in Figure 3(c) are in fact the projections of the boundaries of the aforementioned A-M and M-A two-phase surfaces in the stress-temperature plane. The constant stress hysteresis loop in Figure 3(a) is the intersection curves of the phase diagram in Figure 3(d) with the zero-stress plane. The constant stress hysteresis loop slope also represents the thermal expansion coefficient for singlephase austenite and single-phase martensite, as illustrated in Figure 3(d). The slope of the singlephase surfaces measures the Young's modulus under the uniaxial loading condition.

The graphical representation of the phase diagram in Figure 3(d) can be mathematically described by various constitutive models with different assumptions and simplifications. Muller and Xu (1991) proposed a one-dimensional phenomenological model to study the stress-induced hysteresis based on macroscale behaviors of SMAs, which was similar to that developed by Fedelich and Zanzotto (1991). Liang and Rogers (1990, 1992) developed a one-dimensional model and later extended it to a multi-dimensional one based on both micromechanics and macromechanics. Another approach was conducted by Muller and Seelecke (2001) by utilizing the free-energy distribution between the austenite and martensite phases to model the hysteresis behavior. This method was continued in later studies (Chang et al., 2006; Muller and Bruhns, 2006).

There are quite a few indices to compare the elastocaloric materials. Mechanical performance can be evaluated by the maximum recoverable strain, yield stress and fatigue life. From the energy conversion perspective, the latent heat, latent heat energy density and energy conversion efficiency are important. The latent heat can be measured by differential scanning calorimetry 
(DSC) following a thermally driven phase transformation process as illustrated in Figure 3 (a), or by direct measure of the adiabatic temperature span, i.e. $\Delta T_{\text {ad }}$, when assuming the entire latent heat is absorbed by the elastocaloric material itself during the stress induced phase change process as shown in Figure 3(b). The relation between the latent heat and the adiabatic temperature span is shown in Eq. (2). By evaluating the latent heat from the system application perspective, a non-dimensional number as the ratio between the latent heat and the sensible parasitic heat loss can be used (Qian et al., 2015a), as demonstrated by Eq. (3).

$$
\begin{aligned}
& \Delta T_{a d}=\left.\frac{L}{c_{p}}\right|_{S} \\
& \gamma=\frac{\Delta T_{a d}}{\Delta T_{l i f t}}
\end{aligned}
$$

The latent heat measures the mass-based energy density. Space is another limiting factor in the applications of cooling systems in real life, and therefore, volumetric energy density is also important. Liquid-vapor phase change involves more molecular degrees of freedom than that of solid-to-solid phase change, and therefore, the mass-based latent heat of liquid-vapor phase change is more than 10 times of the mass-based latent heat of elastocaloric materials. However, solid is denser than liquid. As a result, the volumetric energy density difference between elastocaloric materials and the traditional liquid refrigerant in vapor compression systems becomes less. The definition of volumetric energy density is shown in Eq. (4). For example, the mass-based energy density for $\mathrm{Ni}-\mathrm{Ti}$ and a typical conventional refrigerant $\mathrm{R} 134 \mathrm{a}$ are $12 \mathrm{~J} \cdot \mathrm{g}^{-1}$ and $182 \mathrm{~J} \cdot \mathrm{g}^{-1}$, respectively, while the $E D$ for them are $82 \mathrm{MJ} \cdot \mathrm{m}^{-3}$ and $215 \mathrm{MJ} \cdot \mathrm{m}^{-3}$.

$$
E D=\rho \cdot L
$$

Coefficient of performance on the material level, i.e. $\mathrm{COP}_{\text {mat }}$, measures the energy conversion efficiency from the intrinsic material properties only, by assuming that the materials undergo the specific cooling cycle with ideal system configuration, such as $100 \%$ driver efficiency, $100 \%$ regeneration or HR efficiency, $100 \%$ recoverable unloading energy and no auxiliary power 
consumption. The $\mathrm{COP}_{\text {mat }}$ depends on operating temperatures, and therefore, identical basis is needed to guarantee a fair comparison. Nevertheless, it is a material performance metric to compare different elastocaloric materials. A detailed derivation of $\mathrm{COP}_{\text {mat }}$ for elastocaloric materials is available in Qian et al. (2015b) based on a method applied for elastocaloric heat engine study from literature (Ziolkowski, 1993). The derived equation is shown in Eq. (5). It is under the reverse Stirling cycle, as to be introduced in section 3, where $T_{\mathrm{c}}$ and $T_{\mathrm{h}}$ stand for temperatures of the low temperature heat source and high temperature heat sink, respectively. It should also be noted that the reverse Stirling cycle is different from a Carnot cycle and the isothermal phase transformation of the elastocaloric material requires specific conditions, which are not always given, as to be discussed in section 3 .

$C O P_{\text {mat }}=\frac{q_{c}\left(T_{c}\right)}{w_{+}\left(T_{h}\right)-w_{-}\left(T_{c}\right)}=\frac{T_{c} \Delta s-A}{\left(T_{h}-T_{c}\right) \Delta s+2 A}$

$A$ stands for the hysteresis material constant, and can be fitted to the experimental stress-strain data. One observation from Eq. (5) is that hysteresis degrades the $\mathrm{COP}_{\text {mat }}$ in two ways, by reducing the latent heat in the numerator and adding more net work to accomplish the cycle in the denominator. Other different ways to estimate $A$ and $\mathrm{COP}_{\text {mat }}$ were also available (Tusek et al., 2015b). Moya et al. $(2014,2015)$ also reported a similar approach to estimate the energy conversion efficiency of the magnetocaloric, electrocaloric and elastocaloric cooling materials. Unfortunately, this simple approach was not fully-defined since the $\mathrm{COP}_{\text {mat }}$ was independent of the operating temperatures and therefore, could not be used to compare with Carnot cycle COP (ideal material).

Table 1 summarizes the collected data from literature of various SMAs. The adiabatic temperature span $\Delta T_{\text {ad }}$ and $E D$ are presented in Table 1 as well. Standardized testing for more elastocaloric materials is urgently needed since thermal performance measurements were conducted mainly during the past two decades, and current data were only available for a few candidates. 
Figure 4 further visualizes the comparison of elastocaloric materials using the two indices in Eq. (3) and Eq. (5). Note that $T_{\mathrm{c}}=283 \mathrm{~K}$ and $T_{\mathrm{h}}=293 \mathrm{~K}$ have been arbitrarily chosen as the identical comparison basis for various SMAs following the previous work (Qian et al., 2015b). The performance of a single material with identical composition may vary significantly under different driving mode. The oval area of each material represents the reported latent heat range and loading-unloading hysteresis uncertainties. From the perspective of both energy conversion and latent heat, Ni-Ti under compression mode, $\mathrm{Cu}-\mathrm{Zn}$ - $\mathrm{Al}$ under tensile mode, and Ti-Ni-Cu under tensile mode are the most promising material candidates so far.

\subsection{Development of Elastocaloric Materials}

Since harvesting the accompanied caloric effect from SMAs has a relative short history compared with their biomedical applications, the term elastocaloric materials in this session is also referred to SMAs directly. Miyazaki and Otsuka (1989) made a comprehensive summary of the SMA development before 1990. Unfortunately, due to application limitation, no thermal performance was reported at that time. A comprehensive review of shape memory materials including SMA, shape memory ceramics and shape memory polymers was carried out by Otsuka and Wayman (1998).

One of the earliest SMAs was reported by Chang and Read (1951) in an Au-Cd alloy (52.5/47.5 wt.\%). Others were focusing on using either solid-state mechanics or using electron-microscope to understand the physics behind the reversible shape transformation phenomena. However, thermal performance was not as important and was barely reported in those early SMAs, including Ag-Cd (Krishnan and Brown, 1973), Au-Cd following study (Lieberman et al., 1955), Ag-Zn (Cornelis and Wayman, 1974) and In-Tl (Basinski and Christian, 1954).

After those early successes in finding binary alloys, researchers later discovered more and more complicated ternary alloys, quaternary and even alloys with more elements. The Ni-based alloys, especially Ni-Ti alloy, had become the most popular SMA and dominated the market after its discovery in 1959 (Buehler et al., 1963) from Naval Ordnance Laboratory, where the Ni-Ti was 
named "nitinol" since then. Based on the phase composition diagram, Ni-Ti binary alloy has three phases, namely B2, R, and B19' (Otsuka and Wayman, 1998), where R phase is an intermediate transitional phase. The A-M phase transformation undergoes the B2-R-B19' phase change process either induced by stress or upon cooling. The reverse phase change from B19' back to B2 is a single step process. This is consistent with the DSC measured results reported in literature (Uchil et al., 2001, Kim and Daly, 2013, Ossmer et al., 2014). This intrinsic two-steps phase change and asymmetric phase change path on the phase diagram determine that $\mathrm{Ni}$-Ti has higher hysteresis during the phase transformation.

Ternary Ni-based alloys were aimed to improve its performance for different applications. Otsuka and Wayman (1998) suggested that copper addition could be used to reduce the stress-hysteresis in the stress-strain curve for pure Ni-Ti alloy, when the copper percentage was less than $10 \%$. Chluba et al. (2015) suggested that fatigue life can be dramatically improved by adding copper to Ni-Ti alloy, which could be up to 10 million cycles for a thin film sample. Copper could also avoid aging effect but reduce the latent heat on the other hand (Bechtold et al., 2012). Extensive studies have been conducted in University of Tsukuba, Japan for Ni-based alloys using other substitutive elements. Adding niobium increased the hysteresis, which was not favorable for energy conversion application, but was convenient for coupling devices (Piao et al., 1992). Ti-NiPd alloy was also studied by Golberg et al. (1995) and Shimizu et al. (1998), but only shape memory alloy with low strain recovery ratio was studied. Ni-Fe-Ga has been recently reported with more than 50\% of Ni-Ti alloy's latent heat and much lower stress (Pataky et al., 2015; Xu et al., 2015). Another simpler formula with 4\% Co was reported by Xiao et al. (2015). Copper-based SMAs were also popular due to their much lower cost than Ni-based SMAs. Binary alloys, including $\mathrm{Cu}-\mathrm{Zn}$ (Romero and Pelegrina, 2003) and Cu-Sn (Miura et al., 1975), were investigated in literatures. Most literatures focused on ternary alloys, since they improved both the mechanical and thermal performance of the SMAs. $\mathrm{Cu}-\mathrm{Au}-\mathrm{Zn}$ was one of the alloy studied in early time (Miura et al., 1974) but unfortunately it had a small adiabatic temperature span. 
University de Barcelona, Spain, was leading the research in studying the thermal performance of other Cu-based SMAs alternatives, including $\mathrm{Cu}-\mathrm{Zn}$-Al (Bonnot et al., 2008), $\mathrm{Cu}-\mathrm{Al}-\mathrm{Ni}$ (Picornell et al., 2004), and Cu-Al-Be (Manosa et al., 1993). Among them, Cu-Al-Ni and Cu-Zn$\mathrm{Al}$ were regarded as the most promising $\mathrm{Cu}$-based materials, since they have demonstrated higher latent heat than other alloys. However, all Cu-based SMAs are facing the same fatal concern of poor fatigue associated with their brittle nature, which limits their real life applications.

Ferrous alloys were not as popular as Ni-based and $\mathrm{Cu}$-based SMAs. Most literatures were focusing on the shape recovery degree for a new composition, or studying phase change physics via their microstructures. Only a few studies addressed the latent heat of ferrous alloys, which were much smaller than $\mathrm{Ni}$-based and $\mathrm{Cu}$-based alloys. The phase transformation temperature range was also narrower. Nevertheless, ferrous alloys do not have fatal issues such as brittleness in $\mathrm{Cu}$-based SMAs, and still have room for improvements, by adding other elements like $\mathrm{Si}, \mathrm{Co}$, and even carbon (Maki, 1998).

It is also worthwhile to mention some latest advances of the so-called multi-caloric materials, which seeks materials with better latent heat when exposed to multiple field interaction, including caloric effect under magnetic field (magnetocaloric), electric field (electrocaloric), uniaxial stress (elastocaloric) and hydrostatic pressure (barocaloric). The only difference between elastocaloric and barocaloric cooling is whether uniaxial force or the isotropic pressure is applied. Coupled magnetocaloric and barocaloric materials have been investigated, including Ni-Mn-In (Manosa et al., 2010), Ni-Mn-Ga (Manosa et al., 2013) and Ni-Mn-In-Co (Lu et al., 2015). Studies in coupled caloric materials in the future may expand the scope of applications.

An update-to-date comprehensive review on the SMAs' fracture mechanism was published by Baxevanis and Lagoudas (2015). Based on this study, the crack propagation mechanism of elastocaloric materials differs significantly from traditional metallic alloys such as steel, due to suppression of crack tips growth during the reversible martensitic phase transformation. More systematic fracture studies are still needed to fully understand and eventually control the fracture 
failure in the future for a successful implementation of elastocaloric materials into the cooling industry.

\section{Elastocaloric cooling cycles}

The cooling capacity and specific work used in the $\mathrm{COP}_{\text {mat }}$ in Eq. (5) are path dependent variables, and therefore, are affected by cycle specifications. Elastocaloric effect is similar to other caloric effects found in solid-state materials such as magnetocaloric effect and electrocaloric effect. Therefore, the cycle design of elastocaloric cooling systems can be similar to the aforementioned two cooling systems.

Kitanovski and Egolf (2006) categorized the viable cycles for magnetocaloric cooling into four categories: Brayton cycle, Ericsson cycle, Carnot cycle and cycle under cascaded regenerator configuration. The Brayton, Ericsson cycle and regenerator cycle concept was also applied for electrocaloric cooling systems analysis (Ozbolt et al., 2014).

The simplest cycle for elastocaloric cooling can de deduced from the analogy to the Brayton cycle as illustrated by Figure 5 (a). The similar concept has been applied for $\mathrm{COP}_{\text {mat }}$ analysis and system performance estimation in literature (Fahler et al., 2012; Schmidt et al., 2013; Qian et al., 2014; Qian et al., 2015b). The $T_{\mathrm{c}}$ and $T_{\mathrm{h}}$ refer to the external HTF temperatures to deliver cooling and reject heat as demonstrated in Figure 2, respectively. The cycle starts with state 1 at austenite phase. By adiabatic loading (uniaxial tension or compression), the latent heat is released and the temperature of the material increases, reaching state 2 via the isentropic process. The transitional state 1' represents the martensitic start state $\mathrm{M}_{\mathrm{s}}$ in Figure 3. Heat is rejected from the material under the same stress from state 2 to state 3 , where the material's temperature approaches the heat sink's HTF temperature of $T_{\mathrm{h}}$. HR occurs next under the same stress to precool the elastocaloric material from state 3 to state 4 . Without the HR, the sensible heat from state 3 to state 4 neutralizes the part of the available cooling latent heat during the unloading process. The mechanical behavior of the elastocaloric material remains the same during the HR process since the material is cooled down in the single-phase martensite. This is similar to the fact that the 
behavior of a liquid does not vary significantly when further cooled down from a subcooled state. With the assist from $\mathrm{HR}$, the unloading process from state 4 to state 5 via the transitional state 5 , $\left(A_{s}\right)$ can reach a much lower temperature than the unloading process without HR. Cooling is delivered to the load via the heat transfer process from state 5 to state 6 . During the HR process, the elastocaloric material is preheated from state 6 back to state 1 . The green arrow in Figure 5 (a) indicates that there is only internal heat transfer between the conjugated two elastocaloric materials beds during the HR process, as indicated by Figure 2. The precooling energy from state 3 to state 4 is identical to the preheating energy from state 6 to state 1 . An ideal "counter-flow" arrangement of HR process allows $T_{4}$ to be equal to $T_{6}$, if the thermal mass of the conjugated two beds are identical (Qian et al., 2015a).

The elastocaloric Stirling cycle in Figure 5 (b) is corresponding to the magnetocaloric Ericsson cycle. It contains two iso-stress heat transfer processes and two isothermal phase change processes. The cycle begins at unstressed state 1, and is loaded to state 1' before the phase change begins. Different from Brayton cycle, the elastocaloric material is cooled during the martensitic phase transformation process from state 1' to state 2 , and therefore keeps a constant temperature while releasing the latent heat. The iso-stress HR process from state 2 to state 3 is essentially the same as previously introduced except that it is ideal. Afterwards, the unloading process from state 3 to state 4 via state $3^{\prime}$ takes place with the isothermal heating process, where the conditioned room air is cooled down by the system. The cycle concludes itself by the iso-stress HR process from state 4 back to state 1 .

For reverse Stirling cycle in Figure 5(b), one necessary condition is that the HR is ideal to allow the end of the precooling HR to reach state 3 . If the heat recovery efficiency is not ideal, Figure 5 (c) presents an alternative option by combining a Brayton cycle and a Stirling cycle together as a hybrid cycle. Processes $1 \rightarrow 2$ and $4 \rightarrow 5$ represent the isentropic loading and unloading, respectively, which compensate for the deviation from the ideal HR processes. The rest of the 
cycle are similar to that of the Stirling cycle. The isothermal phase transformation of elastocaloric material also requires the accurate match of phase transformation rate and heat transfer rate.

Figure 6 (a) presents the HTF configuration design to achieve the three single-stage cycles in Figure 5. Only the high temperature HTF flows inside the heat rejection loop (orange lines) around $T_{\mathrm{h}}$ to reject heat from the conjugated two beds to the heat sink. The cooling harvest loop (blue lines) is for low temperature HTF to deliver the cooling energy to the heat source $T_{\mathrm{c}}$. HR loop (purple lines) internally transfers heat between the two beds. The HTF temperature inside the rest of the pipes fluctuates during the cycle, and therefore the thermal mass of both the pipe and the corresponding internal HTF should be minimized. A detailed description on the valve sequences is available (Qian et al., 2014, 2015b).

Figure 6 (b) shows the HTF flow and temperature distribution for a cascaded active elastocaloric regenerator (AECR) configuration (Tusek et al., 2015b). Parallel plates made of elastocaloric materials form rectangular channels and allow HTF to oscillate from left to right. The two heat exchangers located on the left and right sides of the elastocaloric materials beds represent the heat source $\left(T_{\mathrm{c}}\right)$ and heat sink $\left(T_{\mathrm{h}}\right)$, respectively. The color difference along the flow direction represents the temperature distribution. The elastocaloric elements are gripped to be loaded by the driving system. During the first process, the elastocaloric material is loaded adiabatically, causing the temperature of the entire bed to increase. Next, the fluid is pumped through the bed to the HHEX where it rejects heat to the heat sink. The temperature of the elastocaloric material decreases during the following unloading process. The fluid flows in the opposite direction towards the CHEX to deliver cooling to the heat source in the final step. The cycle is similar to the Brayton cycle described in Figure 5 (a). In fact, each local element in the flow direction is operated under a local Brayton cycle, and the entire bed is cascaded in the flow direction. Based on the temperature distribution indicated by Figure 6 (b), only the elastocaloric material adjacent to the HHEX rejects heat to the heat sink, and the rest of the bed is under regeneration. Similarly, only the elastocaloric material adjacent to the CHEX delivers cooling to the heat source. This 
simultaneous heat transfer and HR is also different from the separated heat transfer and HR system configuration in Figure 6 (a) for those of single stage cycle. A more comprehensive description on the active regeneration in the magnetocaloric cooling is provided by Kitanovski and Egolf (2006). In addition, another different layout called 'thermal diodes' can also achieve the active regeneration design in Figure 6 (b) without oscillating water (Kitanovski et al., 2015). When attached to two thermal diodes between the SMA bed and the cooling/heating HTF loop, the thermal diodes design refers to controlling the heat transfer between a single SMA bed to the HTF loop during the active regeneration process other than using mechanical valves to reverse the HTF flow direction. With input power, the manipulation of heat transfer within the thermal diodes can be achieved by using a thin-film Peltier thermoelectric module, mechanical contact or taking advantage of anisotropy of thermal conductivity in some materials. The potential benefit is replacing the bulky mechanical valves by the thermal diodes and reducing the loss associated with reversing HTF flow direction in an active regenerator design.

\title{
4. Elastocaloric cooling system integration
}

\author{
4.1 Elastocaloric Heat Engines \\ System integration is a compromise of various details. The experience from elastocaloric heat \\ engines is reviewed and discussed here to guide the system layout design for future elastocaloric \\ cooling systems.
}

A comprehensive summary of design patents was provided by Schiller (2002), where the various designs in literature were categorized into six groups. A few typical heat engine designs are selected and presented in Figure 7. Banks (1975) invented the first continuously operating SMA heat engine. As illustrated in Figure 7 (a), it was a flywheel (drum) connected with 20 Ni-Ti wires. The eccentric position of the wheel hub caused the Ni-Ti wire to be contracted to the original length when heated and stretched when cooled down, which eventually drove the wheel continuously spinning. Johnson (1977) improved Banks' design by adding the regeneration process and changed the layout accordingly. In his design, the two pulleys had slight different 
diameters. Since one pulley located at the heat source is smaller than the other, the Ni-Ti wire is stretched when leaving the heat source and contracted back to its original shape on its way back. As shown in Figure 7 (b), the counter-flow regenerator located in the middle was designed to exchange sensible heat between two Ni-Ti wires or sheets. Shin et al. (1987) proposed a synchronized twin crank design utilizing coils made of SMA wire, as shown in Figure 7 (c). The coiled SMA wire is similar to a spring, in order to achieve a higher strain and structural deformation. The three aforementioned designs treat the solid-state SMA as fluid and the two heat reservoirs as traditional static heat exchanger, where translation and rotation movements enable SMAs to travel between the two static heat reservoirs. Different from the continuous rotation engine, Figure 7 (d) shows a swing-arm design using SMA wire, which converts the reciprocating motion of SMA into the step rotation of the engine (Kaneko and Enomoto, 2011). The one-way clutch only allows the engine to rotate when the SMA is shrinking while heated. Hot and cold HTFs flow alternatively to cyclically heat and cool the SMA wire. This design concept is entirely different from the previous three in a sense that the SMA wire location is stationary, and HTF flow varies cyclically to drive the cycle. As will be discussed, the system configuration design of elastocaloric cooling system followed these two major groups as well, i.e. stationary or mobile SMAs. In addition, wire/sheet/coil shrinking upon heating and expansion upon cooling are the driving potential for the engine rotation although the configuration between the aforementioned four designs vary significantly. The strain variation cycle driven by heat is identical to the cycle plotted in Figure 3 (a).

\subsection{Drivers}

The driver is the second important feature requiring sufficient considerations during the design. The function of the driver for elastocaloric cooling is similar to the role of the compressor in a vapor compression cooling system, the permanent magnet for a magnetocaloric cooling system, and the electric field for an electrocaloric cooling system. The technical requirement, however, varies significantly. The driver to compress or stretch a solid-state SMA only needs a 5\% 
displacement to induce the martensitic phase change. On the contrast, the specific volume change to compress the gaseous refrigerant for a vapor compression system usually ranges from $200 \%$ to $300 \%$, depending on the fluid. The two order of magnitude difference between the elastocaloric cooling system driver and the gaseous compressor results in the significant difference in the force, bringing the major challenge to the manufacturing and maintenance of the drivers for the elastocaloric cooling systems.

Depending on the system layouts, the driver may need to provide various motion with sufficient force. To minimize any potential friction, the driver loading force direction should be parallel to the motion direction of the elastocaloric material. In other words, a linear driver or a linear actuator is needed. Hence, a summary of the current commercially available linear actuator is presented in Figure 8. Pneumatic linear drive, as shown in Figure 8 (a), is based on the cylinder force from the pressure of compressed air. The major advantage is the use of the easy accessible compressed air. This feature also limits the maximum force that a pneumatic driver can apply, since the pressure of the compressed air usually does not exceed 1.5 MPa in these actuators. Nevertheless, pneumatic linear actuator could be a cost saving option for lab scale or small scale proof-of-concept driver. Figure 8 (b) presents the hydraulic cylinders, which have been used in heavy machinery industry for decades. The application of high pressure (70 MPa) oil requires reinforced structure for the cylinders, which brings up the cost significantly when compared with the pneumatic linear actuators, even though more and more aluminum alloy based hydraulic cylinders have been introduced into the market. The hydraulic cylinders can definitely provide more than sufficient force for any elastocaloric cooling system, and are also more compact than any other alternative options. However, the tradeoff is the cost and low efficiency of the hydraulic pump. The next option shown in Figure 8 (c) is the linear motor. By converting the rotation of the rotor to the relative linear motion between the stator and the rotor, linear motors transform the torque output into linear force and displacement. Unfortunately, most commercially available products of this kind target low load applications. Nevertheless, linear motors may become useful 


\subsection{Performance Assessment Indices}

From a system engineering point of view, there should be some universal indices that can be used to access the performance of any elastocaloric cooling system. These indices are not conflicting with the preexisting performance evaluation metrics, such as the COP, cooling capacity, and system temperature lift $\Delta T_{\text {lift. }}$ Instead, they complement each other to ensure a better understanding of the system performance metrics and how to improve the system performance. The first index introduced here is the time constant measuring how fast the heat transfer is needed from the solid-state elastocaloric material to the HTF. Two time constants, $t_{1}$ and $t_{2}$, are presented in Eqs. (6-7). Eq. (6) evaluates the time for a solid to reach the surrounding fluid temperature (Bergman et al., 2011). The time that the HTF flows through a single elastocaloric materials bed is shown in Eq. (7). The volume in Eq. (6) is the volume of the elastocaloric materials, and $V_{\mathrm{HTF}}$ in Eq. (7) stands for the HTF volume inside the elastocaloric materials bed. The value of the two time constants should be minimized to achieve a higher cycling frequency and cooling capacity. The term $A_{\mathrm{HTF}} \cdot V^{1}$ in Eq. (6) is the heat transfer area to elastocaloric materials' volume ratio, which is the most crucial variable to adjust in different designs for a better performance.

$$
\begin{aligned}
& t_{1}=\left(\rho c_{p}\right)_{S M A} \cdot h^{-1} \cdot\left(\frac{A_{H T F}}{V}\right)^{-1} \\
& t_{2}=V_{H T F} \cdot \dot{V}^{-1}
\end{aligned}
$$

The thermal mass ratio (TMR) term in Eq. (8) needs to be tuned as well. A small TMR deteriorates the system performance since the dead thermal mass of HTF neutralizes the part of the useful cooling and heating capacity, whenever the HR or regeneration is not ideal. This index and its similar variations have been used for other cyclically operated solid-state heat transformation applications in literature, including adsorption chillers (Khan et al., 2007; Qian et al., 2013) and magnetocaloric cooling (Nielsen et al., 2011). 
$T M R=\left(m c_{p}\right)_{S M A} \cdot\left(m c_{p}\right)^{-1}$ HTF,dead

Eq. (9) identifies the last index, which measures the uniformity degree of the martensitic phase transformation inside the entire elastocaloric cooling bed. The phase change is assumed to occur locally when the local stress is above the martensitic start saturation stress. Hence, the $\sigma^{*}$ in Eq. (10) as the logic stress field is used to identify the status of phase distribution, which can be either zero or one. Zero means the local elastocaloric material does not fully transform into martensite, and one means the local martensitic phase change is complete. This index is important since any structural asymmetry in the loading force direction may cause significant non-uniform distribution of stress and reduce the potential cooling capacity accordingly. The index in Eq. (9) should be used during the designing stage by simulation to check those novel designs proposed in the future, especially for those 3D oriented designs.

$$
\begin{aligned}
& \Phi=\iiint_{V} \sigma^{*} d V \cdot V_{S M A}{ }^{-1} \\
& \sigma^{*}=\left\{\begin{array}{lll}
0 & \text { if } & \sigma<\sigma_{A M}(T) \\
1 & \text { if } & \sigma \geq \sigma_{A M}(T)
\end{array}\right.
\end{aligned}
$$

An example of using the first two indices to guide better designs is illustrated by Figure 9. The objective is to improve the performance of a compressive elastocaloric cooling prototype (Qian et al., 2015d) using Ni-Ti tubes. The baseline design is using regular bare Ni-Ti tubes. As pointed out previously, the $A_{\mathrm{HTF}} \cdot V^{1}$ term affects the heat transfer constant significantly, and therefore, the three improvement designs are all aiming at increasing this heat transfer surface to volume ratio. The tube-in-tube design (Qian et al., 2015c) is shown in Figure 9 (a). Smaller tube design uses small diameter tubes. Thinner tube design refers to applying same outer diameter tubes with less wall thickness when compared with the baseline tubes. Figure 9 (b) and (c) demonstrate the effect of the heat transfer time constant $t_{1}$ and TMR, respectively. More efficient heat transfer and HR is achieved by increasing the $A_{\mathrm{HTF}} \cdot V^{1}$ to reduce the heat transfer time constant, and therefore, the 
system COP increases. The COP in Figure 9 (c) increases and then saturates with TMR. The COP enhancement is due to the expected heat loss reduction associated with a reduced HTF thermal mass. Meanwhile, the heat transfer rate decreases with the reduction of HTF thermal mass. The saturation indicates the heat transfer rate penalty matches with the heat loss reduction benefit after the $T M R$ reaches an optimum solution. Detailed case by case analysis is therefore necessary to optimize the structure, geometry and HTF configuration while using these indices.

\subsection{Heat Transfer Enhancement and HTF}

The heat transfer enhancement is contradictory to reducing pressure drop in most heat exchangers. Enhanced surface to increase the heat transfer coefficient $(h)$ and increasing heat transfer surface area $\left(A_{\mathrm{HTF}}\right)$ are the two major methods applied in the heat exchanger industry (Shah and Sekulic, 2003). The three improvement designs in Figure 9 are methods to increase the heat transfer surface area. A few more design candidates following the same idea are discussed here also. Porous structure with SMA has much higher heat transfer surface area but could potentially increase HTF pressure drop. The porosity should be optimized based on $T M R$, due to the compromise between pressure drop and the heat transfer time constant. Fins to enhance heat transfer can be another option.

Choosing HTF is critical as well. When the system configuration design is determined, the system performance assessment indices can be used to select the HTF from the thermal performance perspective. Figure 10 plots a comparison of some common HTFs using the heat transfer time constant in Eq. (6) and the TMR in Eq. (8) as criteria, under the baseline condition specified for Ni-Ti tubes from Qian et al. (2015b). Due to extremely low density of air, it requires more than 100 seconds to complete the heat transfer or HR process. Unless the elastocaloric cooling application requires low operating frequency, such as an energy storage system, air should be avoided as the HTF. Other liquids, including water, salt-water solutions (brines), hydrocarbons, methanol and ethanol, are clustered in a small range. Water and brines have a relatively higher specific heat, and therefore, results in less $T M R$ and better heat transfer time constant. However, 
water and brines are corrosive and require a regular system maintenance. Though most of the SMAs are anticorrosive, the auxiliary parts such as valves and pumps still need protection from rust.

\subsection{Prototypes}

There are a few developed elastocaloric cooling prototypes around the world, and more are still under development. The world first tensile driven elastocaloric cooling prototype was developed using Ni-Ti wires, as shown in Figure 11(a) (Saylor, 2012). The multiple Ni-Ti wires were mounted between two non-parallel synchronized rotating plates. The distance between the two plates on the right hand side point $\mathrm{B}$ was slightly longer than that of point $\mathrm{A}$, and therefore induced the stress and deformation upon rotating the two plates. Ni-Ti wires were stretched to martensite and released latent heat simultaneously while moving towards point B. After reaching point $\mathrm{B}, \mathrm{Ni}-\mathrm{Ti}$ wire started the reverse phase change to absorb heat and provide cooling. Two separate air flows transfer heat with the two groups of $\mathrm{Ni}$-Ti wires. This design follows the identical concept from the first three SMA heat engines introduced in Figure 7(a-c), where the elastocaloric materials were treated as a fluid to move from the two static "heat exchangers", i.e. the two air streams with static flow direction. Therefore, we group this design into the "mobile SMA with steady HTF" category. There were a few major challenges observed from operation of this prototype. The friction caused by associated horizontal force during the $\mathrm{Ni}$-Ti wires stretch was not trivial. In addition, the heat transfer between the air and solid-state Ni-Ti wire deteriorated the system performance, since the heat transfer time constant (Eq. (6)) for air limits the cycling frequency.

The world first compressive driven elastocaloric cooling prototype was reported by Qian et al. (2015d), as shown in Figure 11(b). Two beds consisted of multiple Ni-Ti tubes and steel supporting parts were compressed by a motor driven screw-jack. The symmetric system layout allowed the linear actuator to fully recover the unloading energy, if both Ni-Ti tube beds were pre-compressed $50 \%$. This design is in the same manner as the heat engine design in Figure 7(d), 
where the elastocaloric materials are stationary and HTF cyclically flows to transfer heat.

Eliminating the motion of elastocaloric material beds reduces the friction significantly.

There is another compressive elastocaloric cooling prototype under development by authors, as illustrated by Figure 11(c). There are four beds with $37 \mathrm{Ni}$-Ti tubes in each of them with symmetry design. Hydraulic cylinders were sized accordingly to drive the system, which could save the volume by $74 \%$ and weight by $54 \%$ as compared with the one in Figure 11(b), while the nominal cooling capacity increases four times.

Figure 11(d) presents a tensile driven elastocaloric cooling prototype using Ni-Ti sheet/ribbon by Schmidt et al. (2014, 2015). Unlike the aforementioned two prototypes, instead of using HTF, solid-state heat sink and heat source were implemented. The system was compact without the complicated HTF loop, as compared to Qian et al., (2015d). However, two more linear motors were required to control the contact between the elastocaloric materials and the two solid-state reservoirs separately, where the heat rejection and heat absorption were achieved via solid-solid conduction only. This design may be ideal for a small-scale electric cooling, since scaling up could be challenging due to limitation on heat transfer without the effective HTF. In addition, this design is similar to the design in Figure 11(b) except that the cyclically operated HTF network was replaced by a cyclically operated solid-state heat sink/source with linear motors. As a result, it is also a "stationary SMA with cyclic heat sink/source" design.

Figure 11(e) shows another demonstrator using Ni-Ti foil (Ossmer et al., 2015). The double bridge design consisted of a coupled stacked bridges of Ni-Ti plate, such that when one plate is stressed, the other one is fully released. Similar to Schmidt et al. $(2014,2015)$, solid-state heat source and air as heat sink were used in the demonstrator instead of HTF network. The Ni-Ti plates were driven by motors to contact the stationary heat source, and the additional driving motor for mobile heat sink/source (Schmidt et al., 2014, 2015) was eliminated. As pointed by Ossmer et al. (2015), air has a very large heat transfer time constant, and should not be used as a HTF. 


\section{Conclusions}

Elastocaloric cooling attracts more and more research attentions in the past few years. A successful demonstration of prototypes and any commercial products based on elastocaloric effect requires systematic approach from engineering of the material, cooperating the driver, designing the system layout, heat transfer system optimization and optimum system operation in cooling or heating application. Table 4 summarizes the key issues need to be addressed based on the literatures reviewed while covering the aforementioned aspects. More research efforts on the advances in material, the system integration and the heat transfer engineering are urgently needed for the development of this technology to next level for commercialization.

\section{Acknowledgement}

The authors gratefully acknowledge the support of this effort from the U.S. DOE (ARPA-E DEAR0000131) and the Center for Environmental Energy Engineering (CEEE) at the University of Maryland.

\section{References}

Anon., 2015a. http://kinetic-systems.fr/catalog/88-pneumatic-linear-actuator.html (Retrieved on Nov. 12, 2015).

Anon., 2015b. http://www.bpress.cn/list/di/pic/97/144097.jpg (Retrieved on Nov. 12, 2015).

Anon., 2015c. http://ab.rockwellautomation.com/Motion-Control/Actuator/Integrated-Linear-

Thrusters (Retrieved on Nov. 12, 2015).

Anon., 2015d. http://i00.i.aliimg.com/img/pb/237/826/299/299826237_543.jpg (Retrieved on

Nov. 12, 2015).

Anon., 2015e. http://www.pi-usa.us/products/PiezoActuators/index.php\#PATN (Retrieved on

Nov. 12, 2015). 


\section{Anon., 2015f. http://www.hybrid- \\ racing.com/media/catalog/product/cache/1/image/9df78eab33525d08d6e5fb8d27136e 95/s/k/skun}

k2-billet-crankshaft-339-05-0106-0.jpg (Retrieved on Nov. 12, 2015).

Banks, 1975. USA Patent No. US3913326 A.

Basinski, Z., Christian, J., 1954. Crystallography of deformation by twin boundary movements in indium-thallium alloys. Acta Metall. 2, 101-116.

Baxevanis, T., Lagoudas, D.C., 2015. Fracture mechanics of shape memory alloys: review and perspectives. Int. J. Fract. 191, 191-213.

Bechtold, C., Chluba, C., Lima de Miranda, R., Quandt, E., 2012. High cyclic stability of the elastocaloric effect in sputtered TiNiCu shape memory films. Appl. Phys. Lett. 101, 091903.

Bekker, A., Brinson, L.C., 1997. Temperature-induced phase transformation in a shape memory alloy: phase diagram based kinetics approach. J. Mech. Phys. Solids 45, 949-988.

Bekker, A., Brinson, L.C., 1998. Phase diagram based description of the hysteresis behavior of shape memory alloys. Acta Mater. 46, 3649-3655.

Bergman, T.L., lavine, A.S., Incropera, F.P., Dewitt, D.P., 2011. Fundamentals of heat and mass transfer. John Wiley \& Sons, NJ, USA.

Bonnot, E., Romero, R., Manosa, L., Vives, E., Planes, A., 2008. Elastocaloric effect associated with the martensitic transition in shape memory alloy. Phys. Rev. Lett., 100, 4.

Buehler, W., Gilfrich, J., Wiley, R., 1963. Effect of low temperature phase changes on the mechanical properties of alloys near composition TiNi. J. Appl. Phys. 34, 1475-1477.

Chang, B.C., Shaw, J.A., Iadicola, M.A., 2006. Thermodynamics of shape memory alloy wire: modeling, experiments, and application. Cont. Mech. Thermodyn. 18, 83-118.

Chang, L., Read, T., 1951. Plastic deformation and diffusionless phase changes in metals - The gold-cadmium beta-phase. Trans. Amer. Inst. Mining Metall. Eng. 191, 47-52. 
Chen, Y., Zhang, X., Dunand, D., Schuh, C., 2009. Shape memory and superelasticity in polycrystalline Cu-Al-Ni microwires. Appl. Phys. Lett., 95, 171906.

Chluba, C., Ge, W., Miranda, R., Strobel, J., Kienle, L., Quandt, E., et al., 2015. Ultralow-fatigue shape memory alloy films. Science 348, 1004-1007.

Cornelis, I., Wayman, C., 1974. The shape memory effect in AgZn alloys. Scr. Metall. 8, 13211326.

Cui, J., Wu, Y., Muehlbauer, J., Hwang, Y., Radermacher R., Fackler, S., et al., 2012. Demonstration of high efficiency elastocaloric cooling with large Delta T using NiTi wires. Appl. Phys. Lett. 101, 073904. DOI: 10.1063/1.4746257.

Cui, J., Chu, Y.S., Famodu, O.O., Furuya, Y., Simpers, J.H., James, R.D., 2006. Combinatorial search of thermoelastic shape-memory alloys with extremely small hysteresis width. Nat. Mater. 5, 286-290.

Eggeler, G., Hornbogen, E., Yawny, A., Heckmann, A., Wagner, M., 2004. Structural and functional fatigue of NiTi shape memory alloys. Mater. Sci. Eng. A 378, 24-33.

Fahler, S., Roßler, U.K., Kastner, O., Eckert, J., Eggeler, G., Emmerich, H. et al., 2012. Caloric effects in ferroic materials: new concepts for cooling. Adv. Eng. Mater. 14, 10-19.

Fedelich, B., Zanzotto, G., 1991. One dimensional quasistatic nonisothermal evolution of shapememory material inside the hysteresis loop. Cont. Mech. Thermodyn. 3, 251-276.

Fischer, S., Tomlinson, J., Hughes, P., 1994. Energy and global warming impacts of not-in-kind and next generation CFC and HCFC alternatives. Oak Ridge National Lab, USA. Available online: http://www.afeas.org/tewi/tewi-ii.pdf (Retrieved on Jun. 29, 2015)

Foos, M., Frantz, C., Gantois, M., 1975. Shape memory effect and anelasticity associated with the martensitic transformation in the Stoechiometric Fe3Pt alloy. In Perkins, J., Shape Memory Effects in Alloys (pp. 407-417). Springer, New York, USA. 
Gerlach, D., Alvarado, J., Mina, E., Newell, T., 2002. Analysis of elastomer refrigeration cycles. Proceedings of the $9^{\text {th }}$ International Refrigeration and Air Conditioning Conference, Purdue, USA. Paper 538.

Goetzler, W., Zogg, R., Young, J., Johnson, C., 2014. Energy savings potential and RD\&D opportunities for non-vapor compression HVAC technologies. Available online: http://energy.gov/sites/prod/files/2014/03/f12/NonVapor\%20Compression\%20HVAC\%20Report.pdf (Retrieved on Jun $24^{\text {th }}, 2015$ )

Golberg, D., Xu, Y., Murakami, Y., Morito, S., Otsuka, K., 1995. Characteristics of Ti50Pd30Ni20 high-temperature shape memory alloy. Intermetallics 3, 35-46.

Jani, J., Leary, M., Subic, A., Gibson, M., 2014. A review of shape memory alloy research, applications and opportunities. Mater. Design 56, 1078-1113.

Johnson, A., 1977. USA Patent No. US4055955 A.

Kaneko, K., Enomoto, K., 2011. Development of reciprocating heat engine using shape memory alloy. J. Envir. Eng. 6, 131-139.

Khan, M.Z.I., Alam, K.C.A., Saha, B.B., Akisawa, A., Kashiwagi, T., 2007. Study on a re-heat two-stage adsorption chiller - the influence of thermal mass capacitance ratio, overall thermal conductance ratio and adsorbent mass on system performance. Appl. Therm. Eng. 27, 1677-1685.

Kim, K., Daly, S., 2013. The effect of texture on stress-induced martensite formation in nickeltitanium. Smart Mater. Struct. 22, 075012. DOI: 10.1088/0964-1726/22/7/075012.

Kitanovski, A., Egolf, P.W., 2006. Thermodynamics of magnetic refrigeration. Int. J. Refrigeration 29, 3-21.

Kitanovski, A., Plaznik, U., Tomc, U., Poredos, A., 2015. Present and future caloric refrigeration and heat pump technologies. Int. J. Refrigeration 57, 288-298.

Krishnan, R., Brown, L., 1973. Pseudoelasticity and the strain-memory effect in an Ag-45 at. pct Cd alloy. Metall. Trans. 4, 423-429. 
Liang, C., Rogers, C.A., 1990. One-dimensional thermomechanical constitutive relations for shape memory materials. J. Intel. Mater. Syst. Struct. 1, 207-234.

Liang C., Rogers, C.A., 1992. A multi-dimensional constitutive model for the shape memory alloys. J. Eng. Math. 26, 429-443.

Lieberman, D., Wechsler, M., Read, T., 1955. Cubic to orthorhombic diffusionless phase change - experimental and theoretical studies of AuCd. J. Appl. Phys. 26, 473-484.

Lu, Z.K., Weng, G.J., 1997. Maternsitic transformation and stress-strain relations of shapememory alloys. J. Mech. Phys. Solids 45, 1905-1928.

Lu, B.F., Zhang, P.N., Xu, Y., Sun, W., Liu, J., 2015. Elastocaloric effect in Ni45Mn36.4In13.6Co5 metamagnetic shape memory alloys under mechanical cycling. Mater. Lett. 148, 110-113.

Maki, T., Kobayashi, K., Minato, M., Tamura, I., 1984. Thermoelastic martensite in an ansaged Fe-Ni-Ti-Co alloy. Scr. Metall 18, 1105-1109.

Maki, T., 1998. Ferrous shape memory alloys. In K. Otsuka, C. Wayman, Shape Memory Materials (pp. 129-131). Cambridge University Press. Cambridge, UK.

Manosa, L., Planes, A., Ortin, J., 1993. Entropy change of martensitic transformations in Cubased shape memory alloys. Phys. Rev. B 4, 3611-3619.

Manosa, L., Planes, A., Vives, E., 2009. The use of shape-memory alloys for mechanical refrigeration. Funct. Mater. Lett. 2, 73-78.

Manosa, L., Alonso, D.G., Planes, A., Bonnot, E., Barrio, M., Tamarit, J.L., et al., 2010. Giant solid-state barocaloric effect in the Ni-Mn-In magnetic shape-memory alloy. Nat. Mater. $9,478-481$.

Manosa, L., Planes, A., Acet, M., 2013. Advanced materials for solid-state refrigeration. J. Mater. Chem. A 1, 4925-4936.

McNichols, J.L., Cory, J.S., 1987. Thermodynamics of nitinol. J. Appl. Phys. 61, 972. DOI: 10.1063/1.338151. 
Moya, X., Kar-Narayan, S., Mathur, N.D., 2014. Caloric materials near ferroic phase transitions. Nat. Mater. 13, 439-450.

Moya, X., Defay, E., Heine, V., Mathur, N.D., 2015. Too cool to work. Nat. Phys. 11, 202-205.

Miura, S., Maeda, S., Nakanishi, N., 1974. Pseudoelasticity in Au-Cu-Zn thermoelastic matensite. Phil. Mag. 30, 565-581.

Miura, S., Moruta, Y., Nakanishi, N., 1975. Superelasticity and shape memory effect in Cu-Sn alloys. In Perkins, J., Shape Memory Effects in Alloys (pp. 389-405). Springer, New York, USA.

Miyazaki, S., Otsuka, K., 1989. Development of shape memory alloys. ISIJ Intern. 29, 353-377. Moran, M.J., Shapiro, H.N., Boettner, D.D., Bailey, M.B., 2011. Fundamentals of engineering thermodynamics. John Wiley and Sons, Inc. New York, USA.

Muller, I., H.B., Xu, 1991. On the pseudoelastic hysteresis. Acta Met. Mater. 39, 263-271.

Muller, I., Seelecke, S., 2001. Thermodynamic aspects of shape memory alloys. Math. Comp. Mode. 34, 1307-1355.

Muller, C., Bruhns, O.T., 2006. A thermodynamic finite-strain model for pseudoelastic shape memory alloys. Int. J. Plast. 22, 1658-1682.

Nam, T., Saburi, T., Shimizu, K., 1990. Cu-content dependence of shape memory characteristics in Ti-Ni-Cu alloys. Mater. Trans. JIM 31, 959-967.

Nikitin, S., Myalikgulyev, G., Annaorazov, M., Tyurin, A., Myndyev, R., Akopyan, S., 1992. Giant elastocaloric effect in FeRh alloy. Phys. Lett. A 171, 234-236.

Nielsen, K.K., Tusek, J., Engelbrecht, K., Schopfer, S., Kitanovski, A., Bahl, C.R.H., et al., 2011. Review on numerical modeling of active magnetic regenerators for room temperature applications. Int. J. Refrigeration 34, 603-616.

Ortin, J., Delaey, L., 2002. Hysteresis in shape-memory alloys. Int. J. Non-linear Mech. 37, 12751281. 
Ossmer, H., Lambrecht, F., Gultig, M., Chluba, C., Quandt, E., Kohl, M., 2014. Evolution of temperature profiles in TiNi films for elastocaloric cooling. Acta Mater. 81, 9-20.

Ossmer, H., Miyazaki, S., Kohl, M., 2015. Elastocaloric heat pumping using a shape memory alloy foil device. 2015 Transducers, Anchorage, USA. DOI: 10.1109/TRANSDUCERS.2015.7181026.

Otsuka, K., Wayman, C.K., 1998. Shape memory materials. Cambridge University Press, London, UK.

Otsuka, K., Ren, X., 2005. Physical metallurgy of Ti-Ni-based shape memory alloys. Prog. Mater. Sci. 50, 511-678.

Ozbolt, M., Kitanovski, A., Tusek, J., Poredos, A., 2014. Electrocaloric refrigeration: thermodynamics, state of the art and future perspectives. Int. J. Refrigeration 40, 174188.

Pataky, G.J., Ertekin, E., Sehitoglu, H., 2015. Elastocaloric cooling potential of NiTi, Ni2FeGa, and CoNiAl. Acta Mater. 96, 420-427.

Peyroux, R., Chrysochoos, A., Licht, C., Lobel, M., 1998. Thermomechanical couplings and pseudoelasticity of shape memory alloys. Int. J. Eng. Sci. 36, 489-509.

Piao, M., Miyazaki, S., Otsuka, K., 1992. Characteristics of deformation and transformation in Ti44Ni47Nb9 shape memory alloy. Mater. Trans. JIM 33, 346-353.

Picornell, C., Pons, J., Cesari, E., 2004. Stress-temperature relationship in compression mode in Cu-Al-Ni shape memory alloys. Mater. Trans. 45, 1679-1683.

Planes, A., Manosa, L., Rios-Jara, D., Ortin, J., 1992. Martensitic transformation of Cu-based shape-memory alloys: Elastic anisotropy and entropy change. Phys. Rev. B 45, 76337639.

Qian, S., Gluesenkamp, K., Hwang, Y., Radermacher, R., Chun, H.H., 2013. Cyclic steady state performance of adsorption chiller with low regeneration temperature zeolite. Energy 60, 517-526. 
Qian, S., Ling, J., Hwang, Y., Radermacher, R., 2014. Dynamic performance of a compression thermoelastic cooling air-conditioner under cyclic operation mode. Proceedings of the $15^{\text {th }}$ International Refrigeration and Air Conditioning Conference, Purdue, USA. Paper 1411.

Qian, S., Ling, J., Muehlbauer, J., Hwang, Y., Radermacher, R., 2015a. Study on high efficient heat recovery cycle for solid-state cooling. Int. J. Refrigeration 55, 102-119.

Qian, S., Ling, J., Hwang, Y., Radermacher, R., Takeuchi, I., 2015b. Thermodynamic cycle analysis and numerical modeling of thermoelastic cooling systems. Int. J. Refrigeration $56,65-80$.

Qian, S., Alabdulkarem, A., Ling, J., Muehlbauer, J., Hwang, Y., Radermacher, R., Takeuchi, I., 2015c. Performance enhancement of a compressive thermoelastic cooling system using multi-objective optimization and novel designs. Int. J. Refrigeration, 57, 62-76.

Qian, S., Wu, Y., Ling, J., Muehlbauer, J., Hwang, Y., Takeuchi, I., Radermacher, R., 2015d. Design, development and testing of a compressive thermoelastic cooling prototype. International Congress of Refrigeration 2015, Japan. Paper 0092.

Recarte, V., Saez, R.B.P., Bocanegra, E.H., No, M.L., Juan, J.S., 1999. Dependence of the martensitic transformation characteristics on concentration in $\mathrm{Cu}-\mathrm{Al}-\mathrm{Ni}$ shape memory alloys. Mater. Sci. Eng. A 273, 380-384.

Romero, R., Pelegrina, J., 2003. Change of entropy in the martensitic transformation and its dependence in Cu-based shape memory alloys. Mater. Sci. Eng. A, 354, 243-250.

Saylor, A., 2012. ARPA-E summit technology showcase. http://www.energy.gov/articles/2012arpa-e-summit-technology-showcase (Retrieved on Nov. 12, 2015)

Schiller, E.H., 2002. Heat engine driven by shape memory alloys; prototyping and design. Master Thesis. Virginia Polytech Institute and State University, Blacksburg, VA, USA.

Schmidt, M., Schutze, A., Seelecke, S., 2013. Cooling efficiencies of a NiTi-based cooling process. Proceedings of the ASME SMASIS 2013, Snowbird, UT, USA. 
Schmidt, M., Schutze, A., Seelecke, S., 2014. Experimental investigation on the efficiency of a control dependent NiTi-based cooling process. Proceedings of the ASME SMASIS 2014, Newport, RI, USA.

Schmidt, M., Schutze, A., Seelecke, S., 2015. Scientific test setup for investigation of shape memory alloy based elastocaloric cooling processes. Int. J. Refrigeration 54, 88-97.

Shimizu, S., Xu, Y., Okunishi, E., Tanaka, S., Otsuka, K., Mitose, K., 1998. Improvement of shape memory characteristics by precipitation-hardening of Ti-Pd-Ni alloys. Mater. Lett. $34,23-29$.

Shah, R.K., Sekulic, D.P., 2003. Fundamentals of heat exchanger design. John Wiley \& Sons, NJ, USA.

Shin, M., Kim, C., Chuang, Y., Jee, K., 1987. USA Patent No. US4683721 A.

Sittner, P., Novak, V., 2000. Anisotropy of martensitic transformations in modeling of shape memory alloy polycrystals. Int. J. Plast. 16, 1243-2168.

Sutou, Y., Omori, T., Wang, J.J., Kainuma, R., Ishida, K., 2004. Characteristics of Cu-Al-Mnbased shape memory alloys and their applications. Mater. Sci. Eng. A 378, 278-282.

Tusek, J., Engelbrecht, K., Mikkelsen, L.P., Pryds, N., 2015a. Elastocaloric effect of Ni-Ti wire for application in a cooling device. J. Appl. Phys. 177, 124901. DOI: 10.1063/1.4913878.

Tusek, J., Engelbrecht, K., Solsona, R.M., Manosa, L., Vives, E., Mikkelsen, L.P. et al., 2015b. The elastocaloric effect: a way to cool efficiently. Adv. Energy Mater. 1500361. DOI: 10.1002/aenm.201500361.

Uchil, J., Mahesh, K.K., Kumara, K.G., 2001. Calorimetric study of the effect of linear strain on the shape memory properties of nitinol. Phys. B Cond. Matt. 305, 1-9.

Xiao, F., Fukuda, T., Kakeshita, T., 2013. Significant elastocaloric effect in a Fe-31.2Pd (at. \%) single crystal. Appl. Phys. Lett. 102, 161914.

Xiao, F., Jin, M., Liu, J., Jin, X., 2015. Elastocaloric effect in Ni50Fe19Ga27Co4 single crystals. Acta Mater. 96, 292-300. 
Xu, Y., Lu, B., Sun, W., Yan, A., Liu, J., 2015. Large and reversible elastocaloric effect in dualphase Ni54Fe19Ga27 superelastic alloys. Appl. Phys. Lett. 106, 201903. DOI: 10.1063/1.4921531.

Zak, G., Kneissl, A.C., Zatulskij, G., 1996. Shape memory effect in cryogenic Cu-Al-Mn alloys. Scr. Mater. 34, 363-367.

Ziolkowski, A., 1993. Theoretical analysis of efficiency of shape memory alloy heat engines (based on constitutive models of pseudoelasticity). Mechanics of Materials, 16, 365-377. 

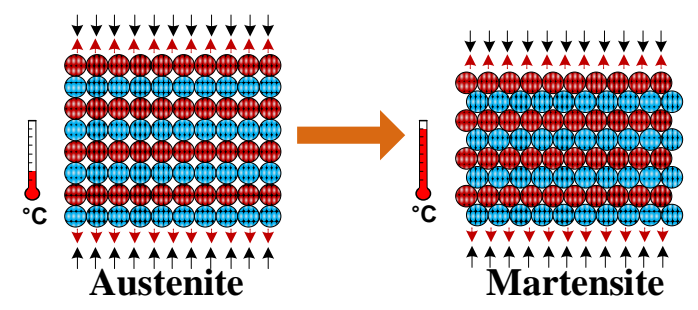

(a) when the stress is imposed $\left(\sigma_{\text {sat }}<\sigma_{\text {sys }}\right)$

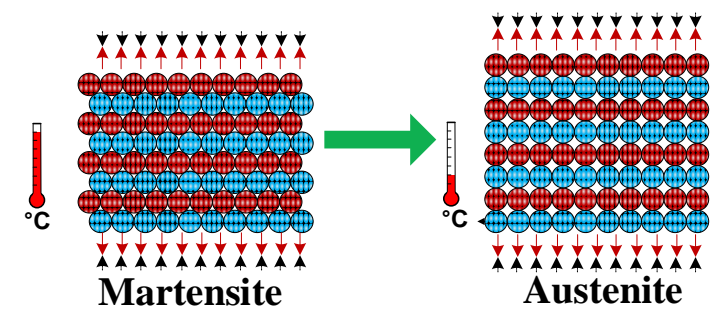

(b) when the stress is released $\left(\sigma_{\text {sat }}>\sigma_{\text {sys }}\right)$

Figure 1: Illustration of the elastocaloric effect found in shape memory alloys. 


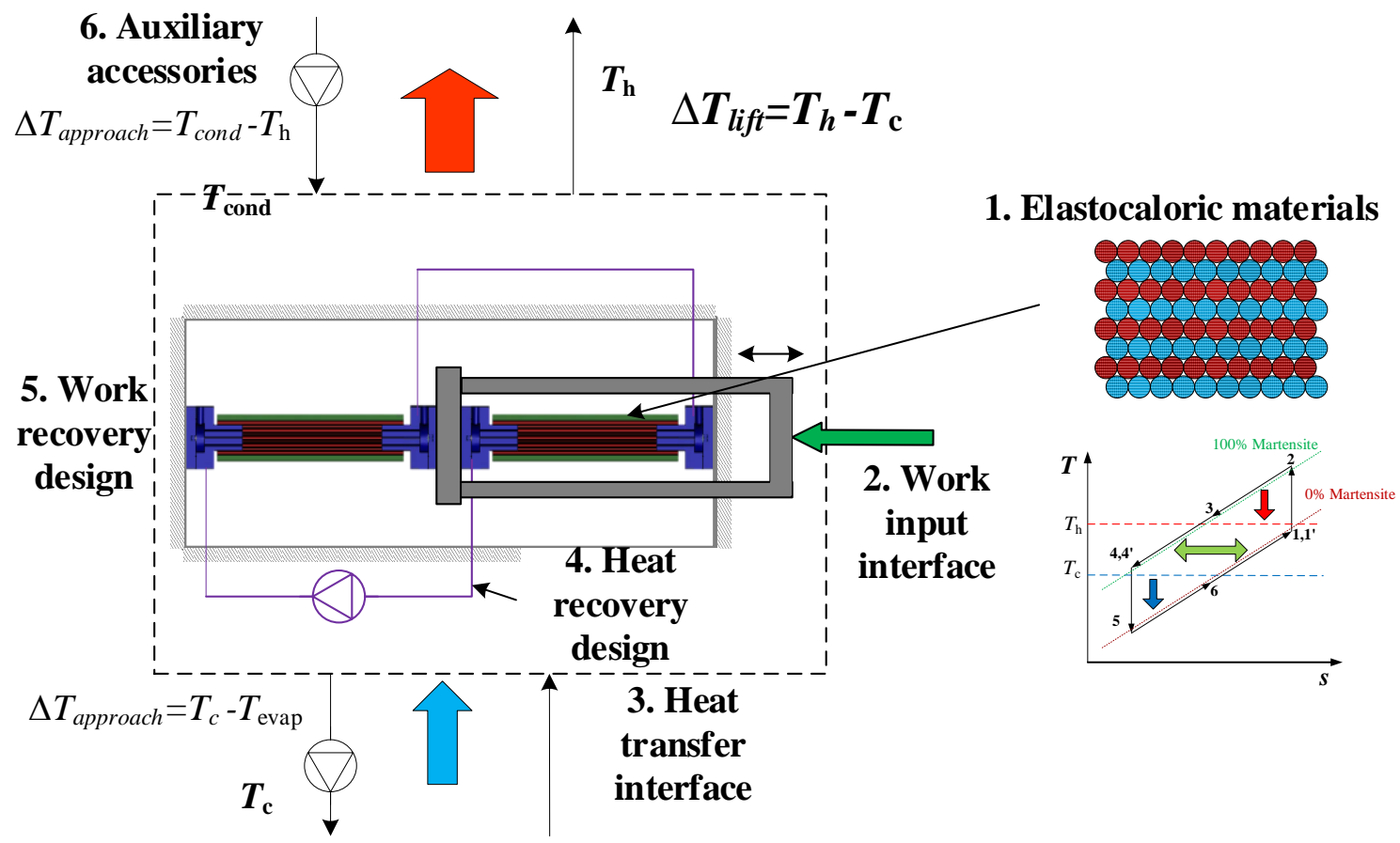

Figure 2: Illustration of the typical features of an elastocaloric cooling system. 


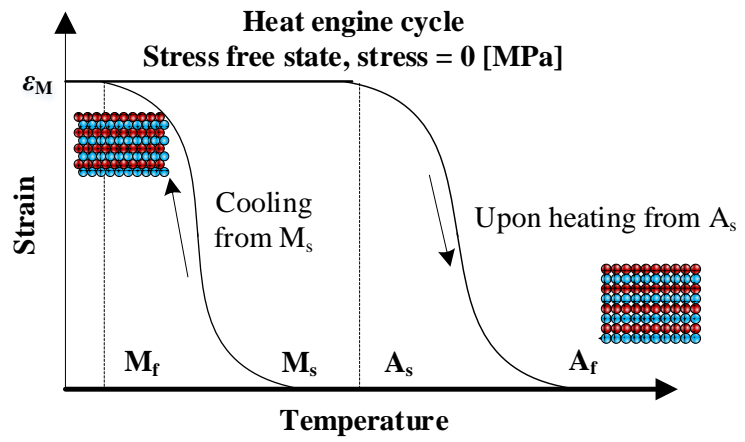

(a) Temperature hysteresis for a heat engine cycle under the stress-free state

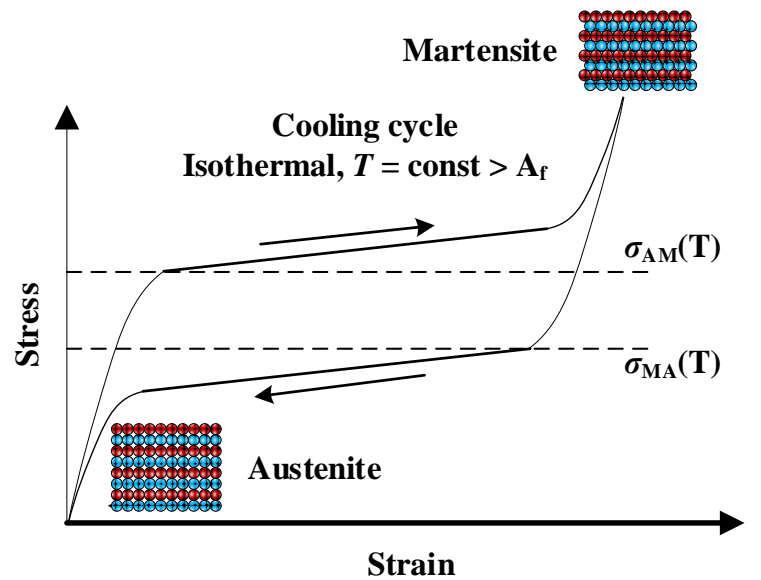

(b) Stress and temperature hysteresis for a cooling cycle under the isothermal condition

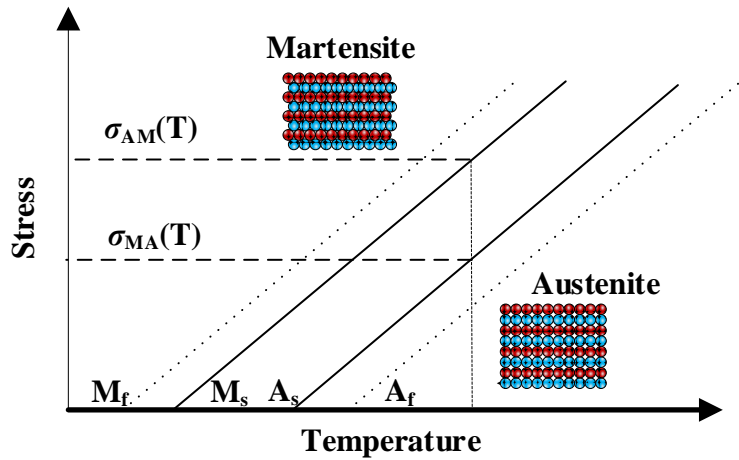

(c) Graphical interpolation of the constitutive relation for elastocaloric materials 


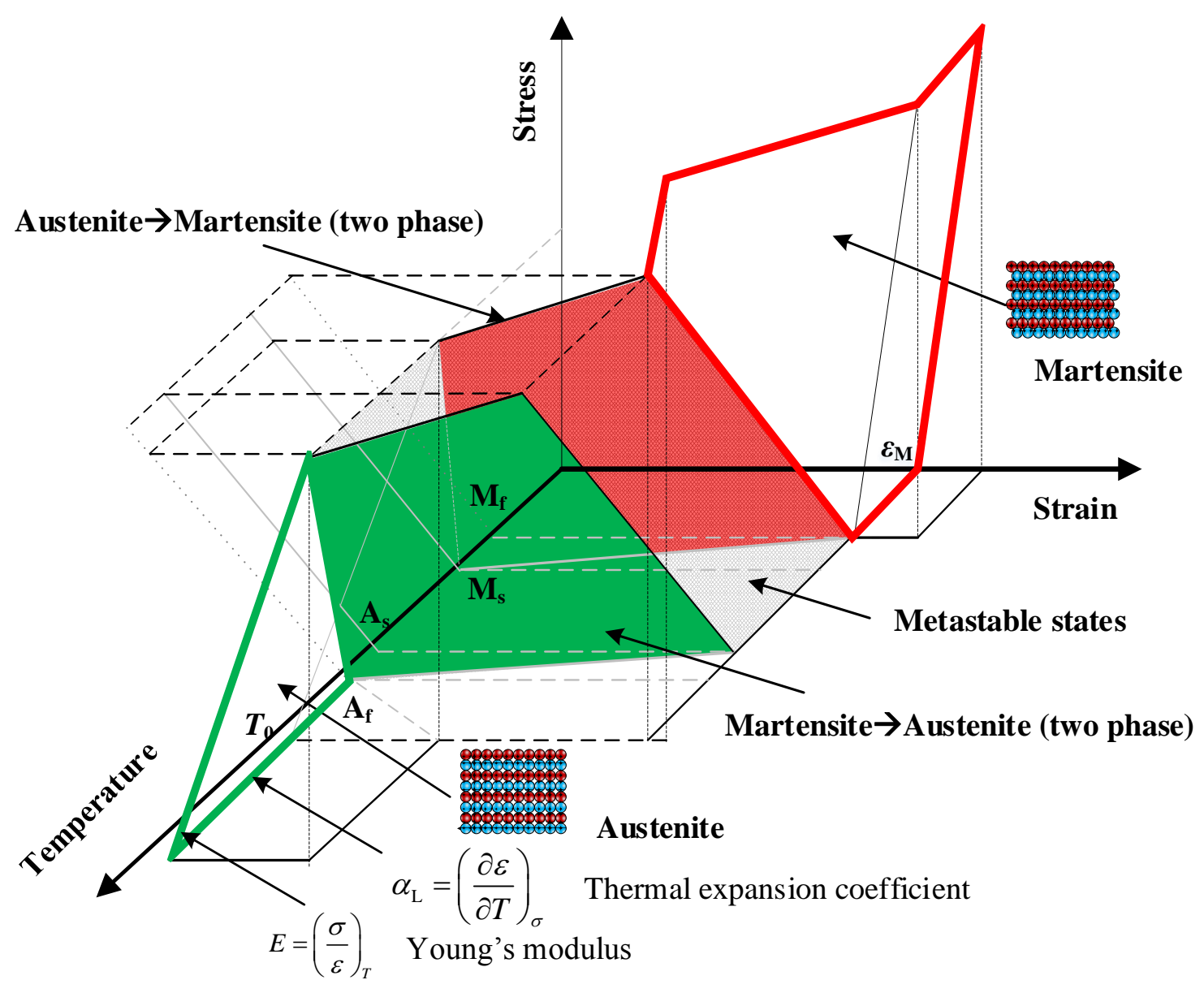

(d) A three dimensional phase diagram

Figure 3: Graphical represent of hysteresis curves, constitutive relation and a three-dimensional figure of the phase diagram of elastocaloric materials. 


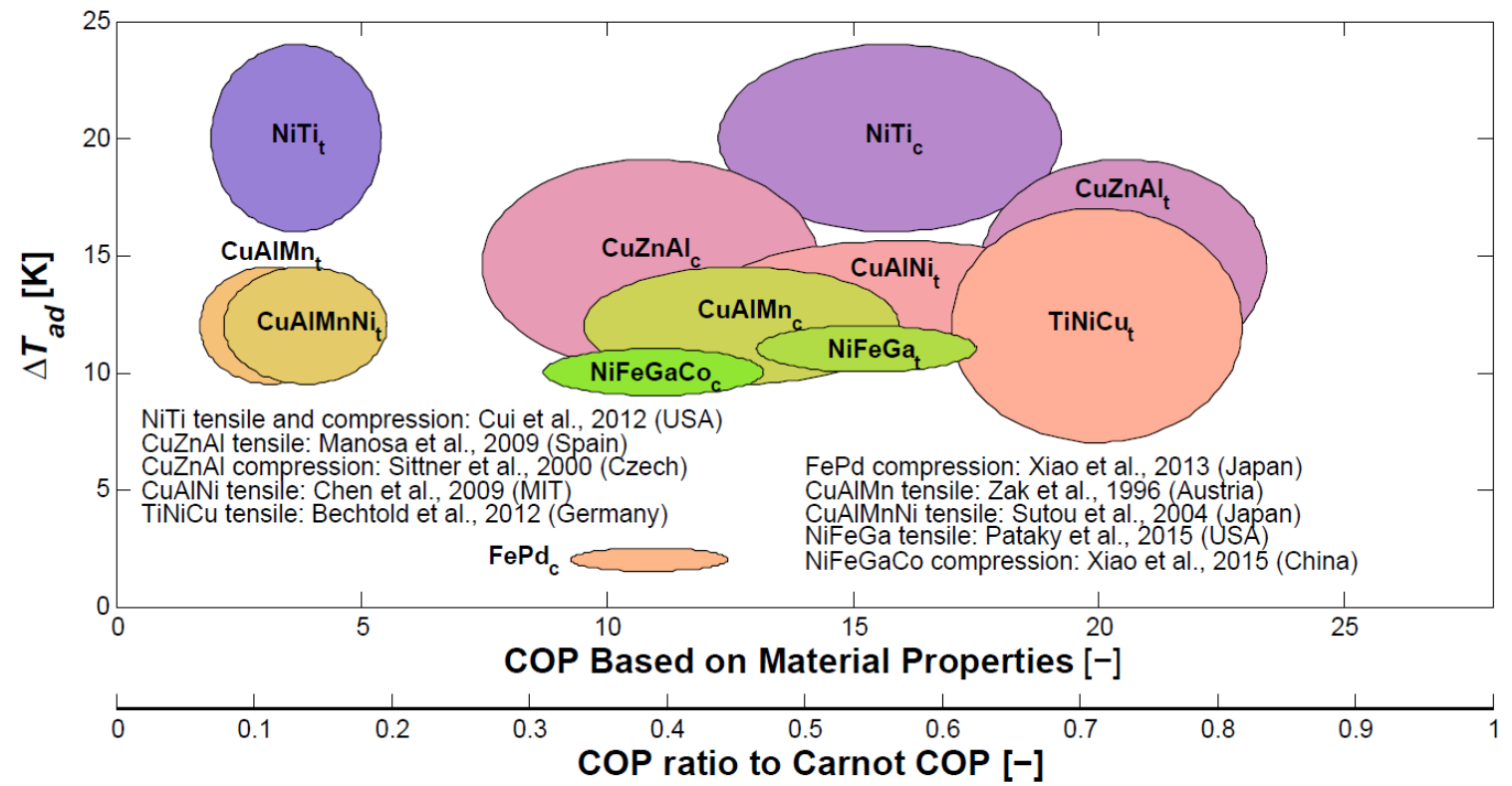

Figure 4: Performance summary of elastocaloric materials $(\mathrm{Tc}=283 \mathrm{~K}$ and $\mathrm{Th}=293 \mathrm{~K}$ under).

("t" means tension, and "c" stands for compression) 

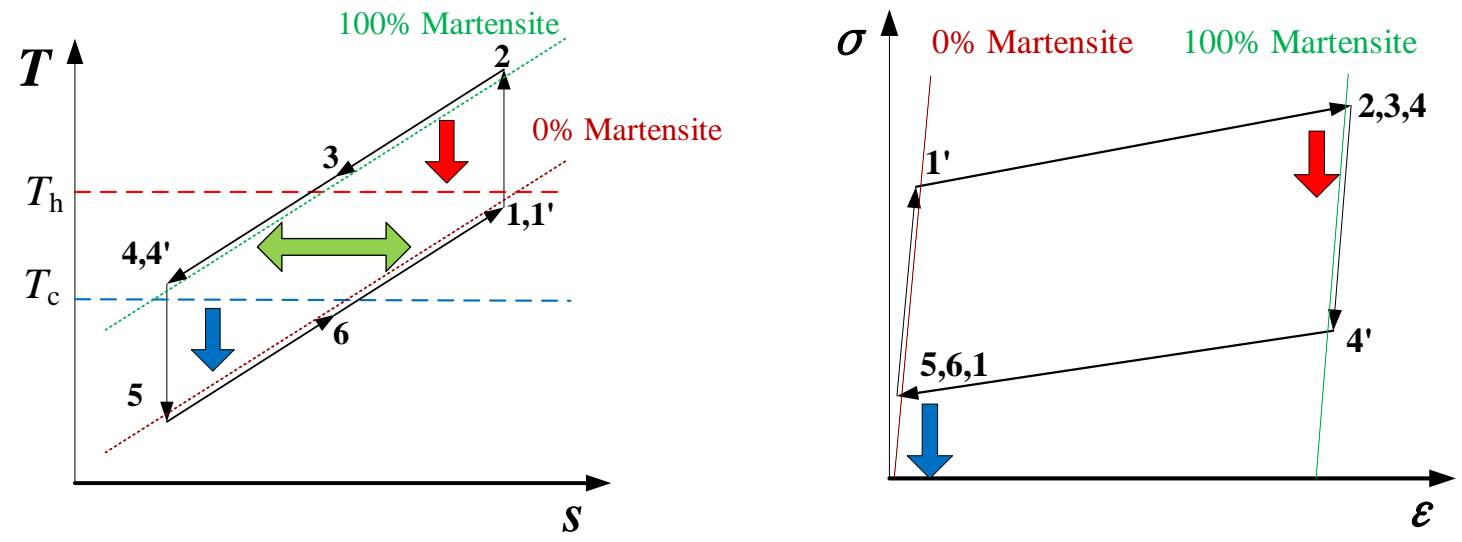

(a) Single stage Brayton cycle
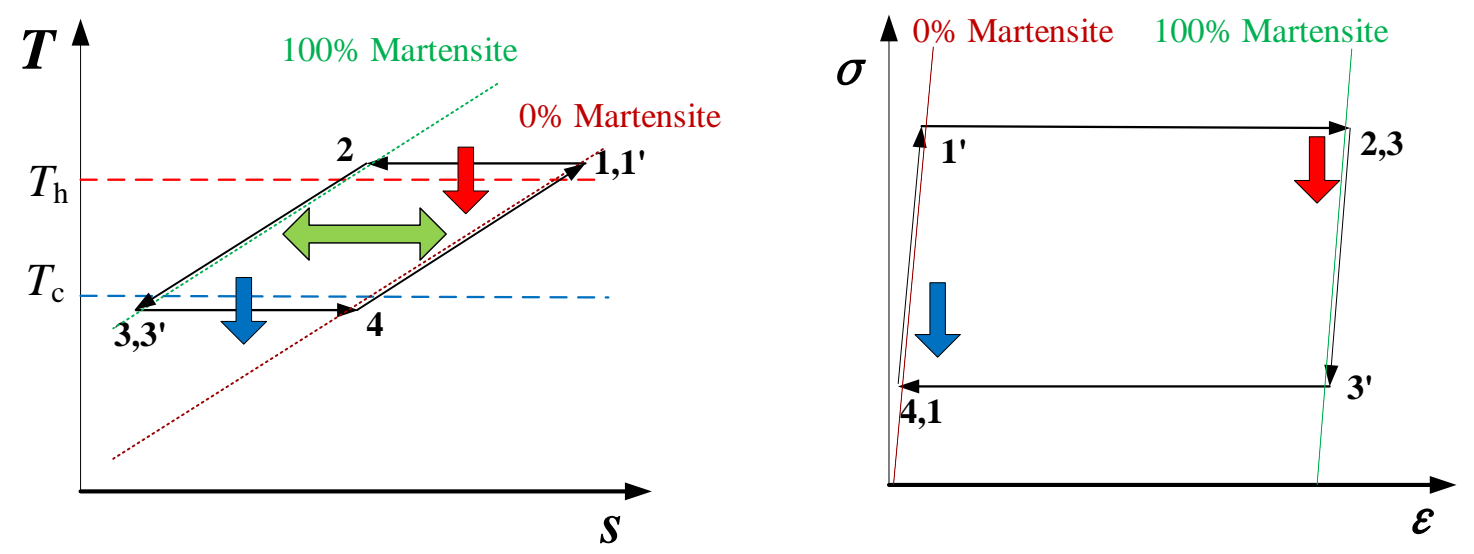

(b) Single stage Stirling cycle
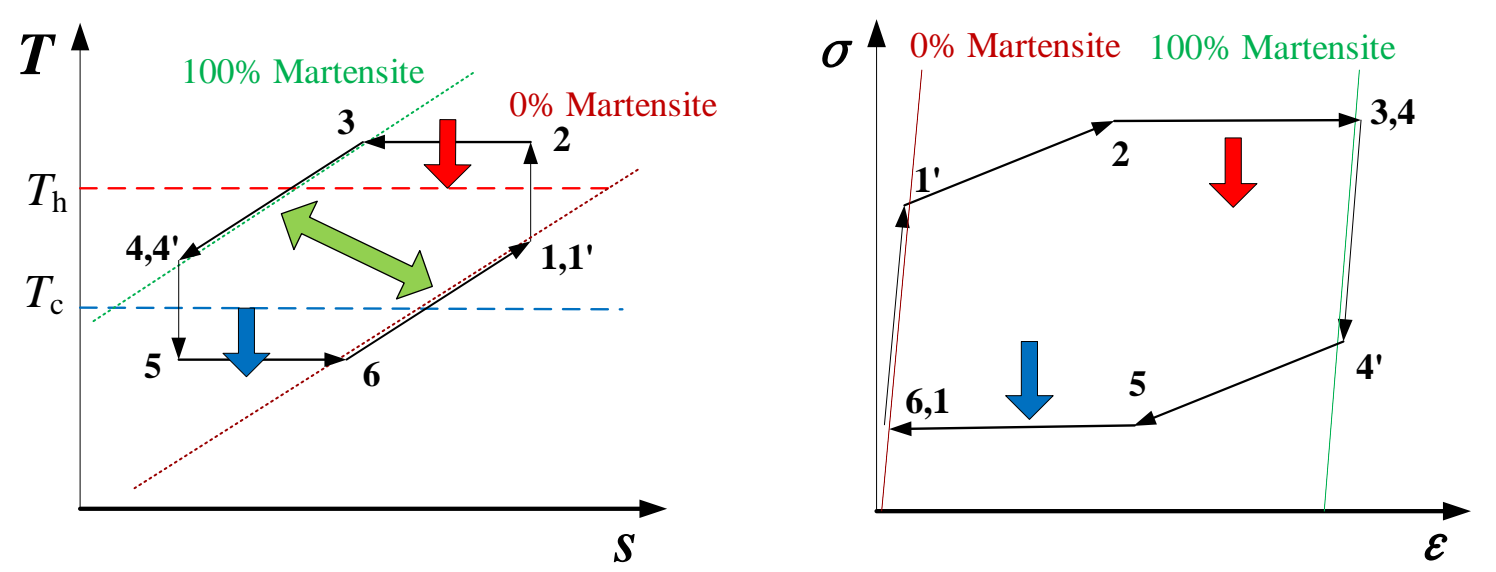

(c) Single stage hybrid cycle

Figure 5: Possible single stage cooling cycles based on elastocaloric effect (Qian et al., 2015b). 


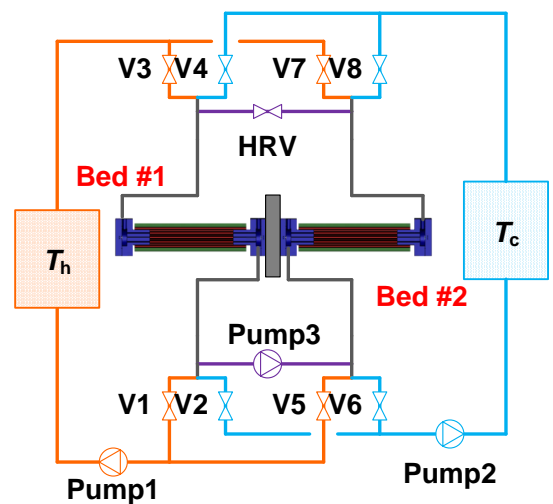

(a) A single-stage design based on

elastocaloric effect (Qian et al., 2015b)
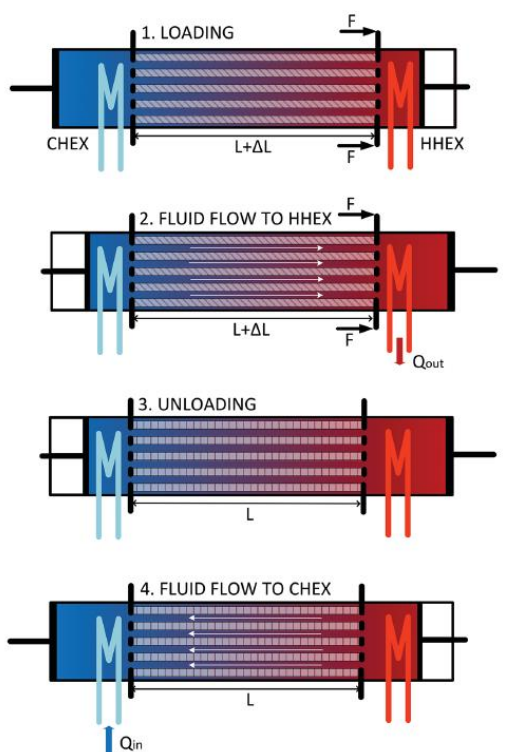

(b) An active elastocaloric regenerator

(AECR) design based on elastocaloric effect

(Tusek et al., 2015b)

Figure 6: Illustration of different system heat transfer configurations. 


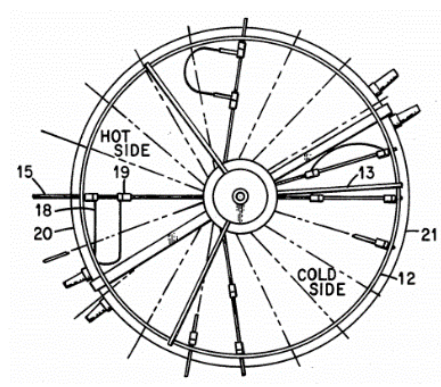

(a) Rotating flywheel design (Banks, 1975)

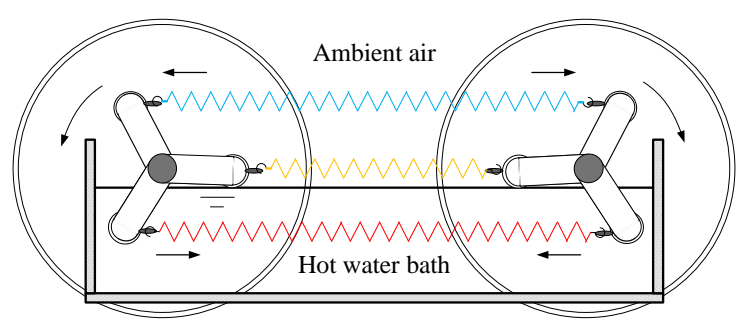

(c) Two pulleys design

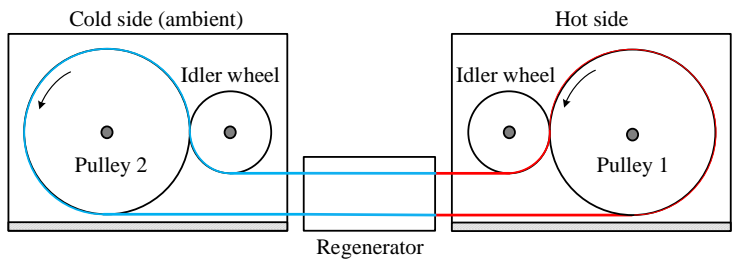

(b) Twin-crank design

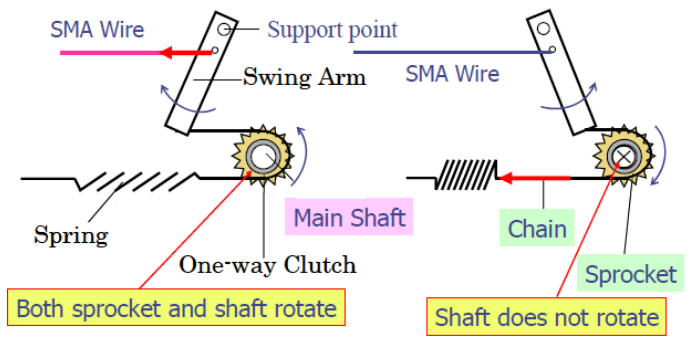

(d) Single swing arm design (Kaneko and

Figure 7: Summary of a few typical heat engines using elastocaloric materials. 


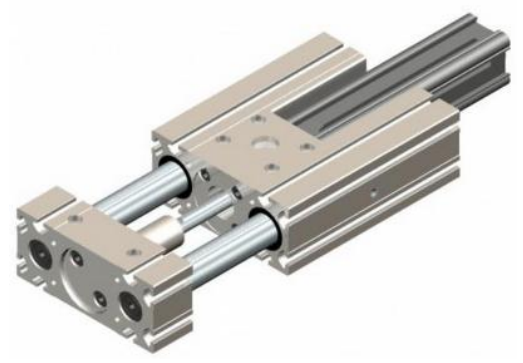

(a) Pneumatic (fluid usually air, cheap, less than $200 \mathrm{kN}$, large)

(Anon., 2015a)

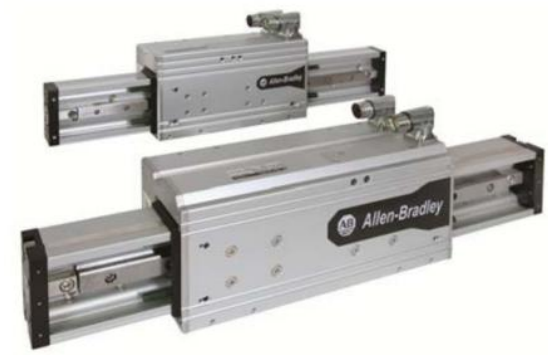

(c) Linear motors (low force, products on market are less than $10 \mathrm{kN}$, can be used as parasitic motors for other moving parts in the system)

(Anon., 2015c)

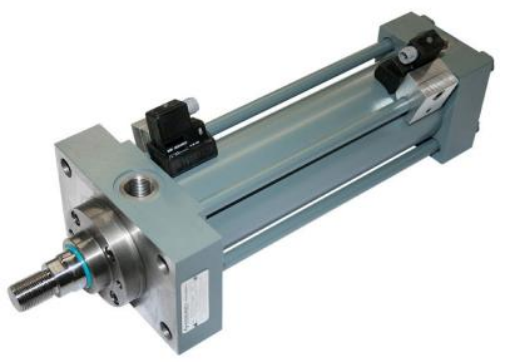

(b) Hydraulic (high pressure fluid, expensive, products of $7000 \mathrm{kN}$ available, compact)

(Anon., 2015b)

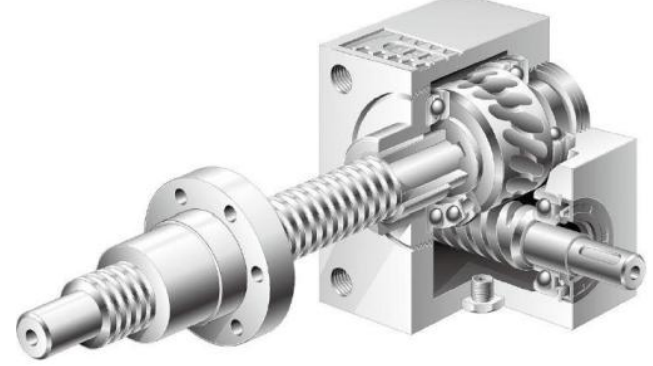

(d) Screw-jack (moderate precision, large force, up to $1,000 \mathrm{kN}$ products available, large profile, a gearbox is usually required for the motor) (Anon., 2015d)

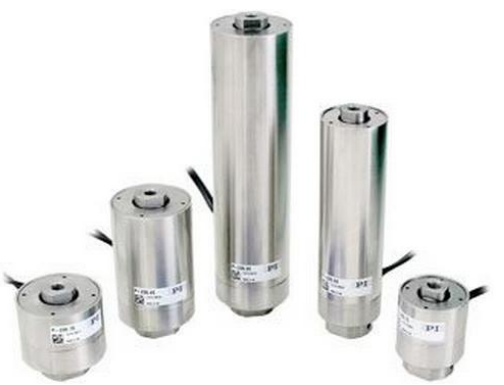

(e) Piezoelectric (high precision, multi-layer products up to $100 \mathrm{kN}$, displacement up to 10 mm) (Anon., 2015e)

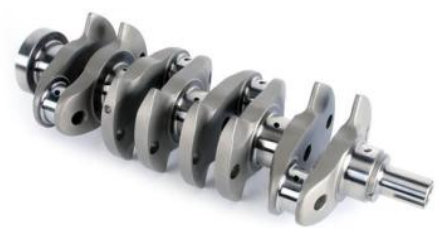

(f) Crankshaft (moderate precision, moderate to high force) (Anon., 2015f)

Figure 8: Summary of tension and compression linear driving system options for elastocaloric cooling systems. 

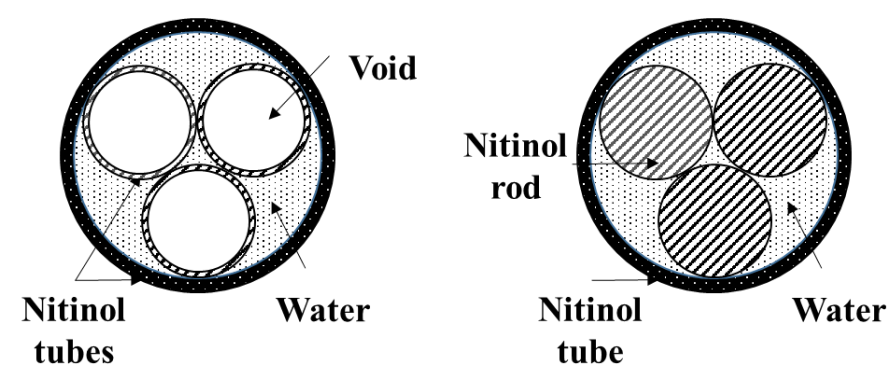

(a) Two novel designs to improve the baseline design in a compressive prototype using Ni-Ti tubes (Qian et al., 2015c)

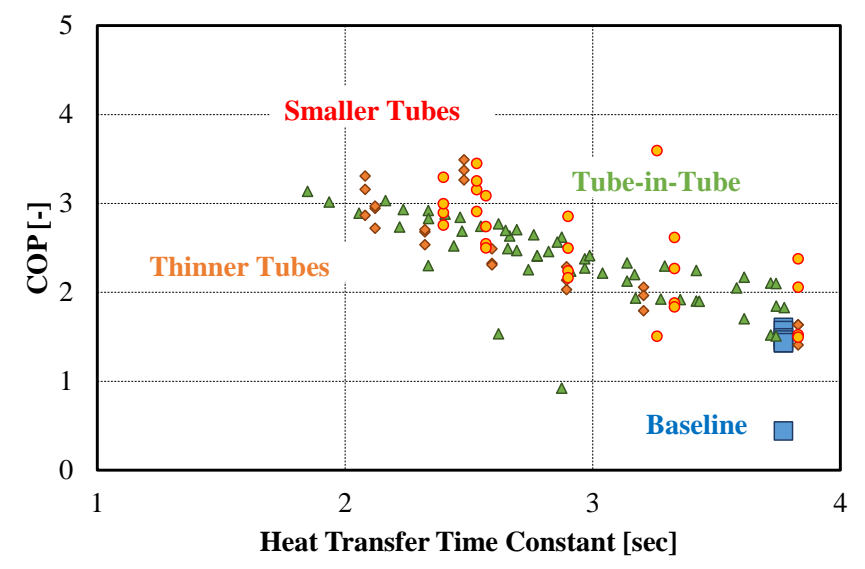

(b) Effect of the heat transfer time constant

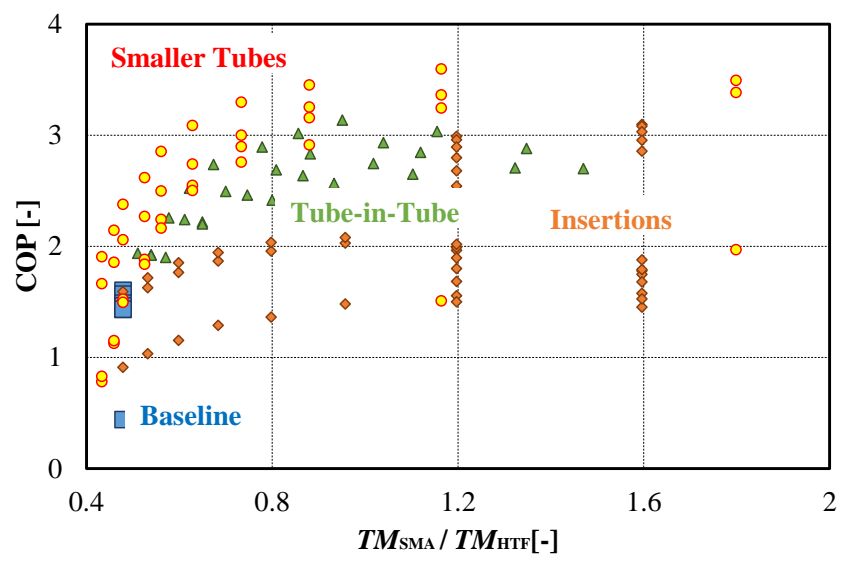

(c) Effect of the thermal mass ratio between active elastocaloric materials and parasitic parts

Figure 9: Effect of varying the performance assessment indices on the elastocaloric cooling system performance. 


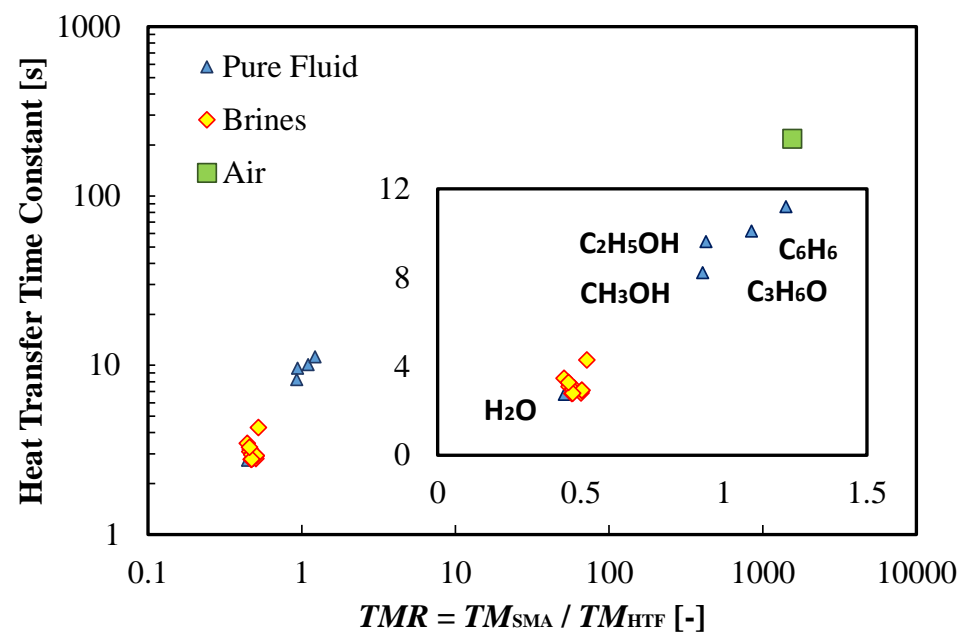

Figure 10: HTF comparison using the heat transfer time constant and TMR as indices. 

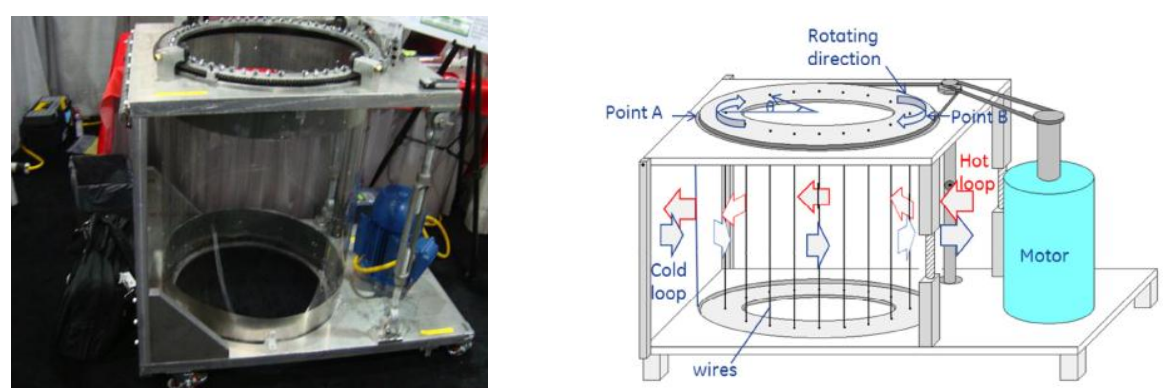

(a) University of Maryland, tension, Ni-Ti wire based rotary prototype, mobile SMA, steady HTF, with WR, no HR, $0.5 \mathrm{~Hz}$ operating frequency (Saylor, 2012)
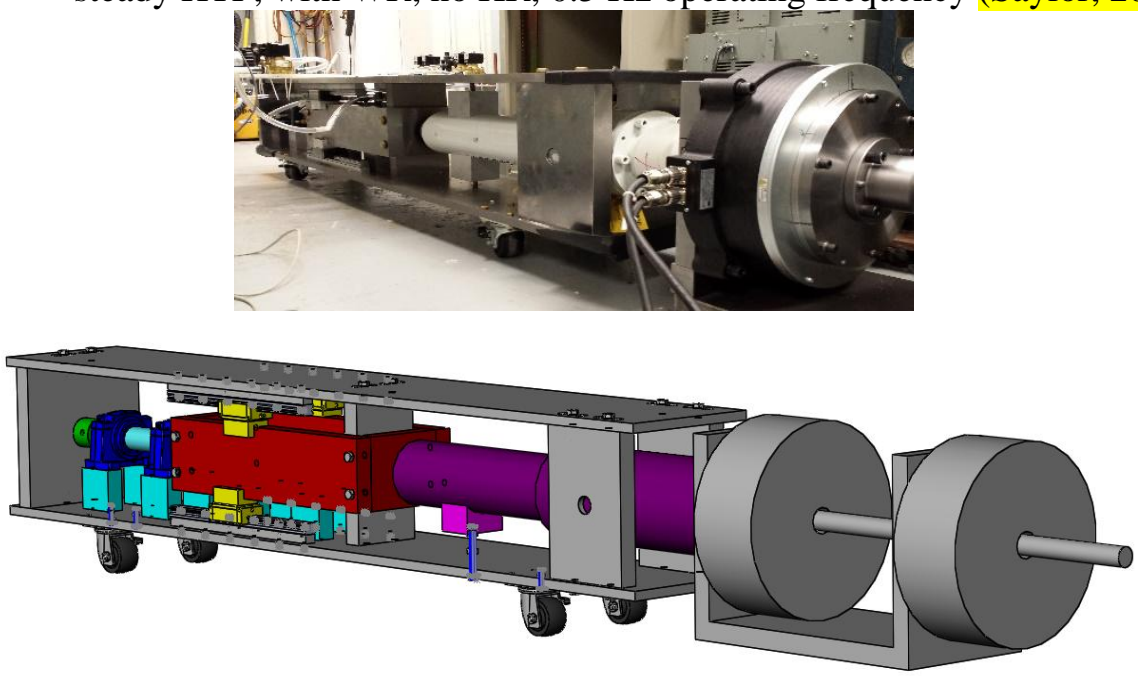

(b) University of Maryland, compression, Ni-Ti tubes, driven by screw-jack, stationary SMA, cyclic HTF, with WR, with HR, $0.05 \mathrm{~Hz}$ operating frequency (Qian et al., 2015d)

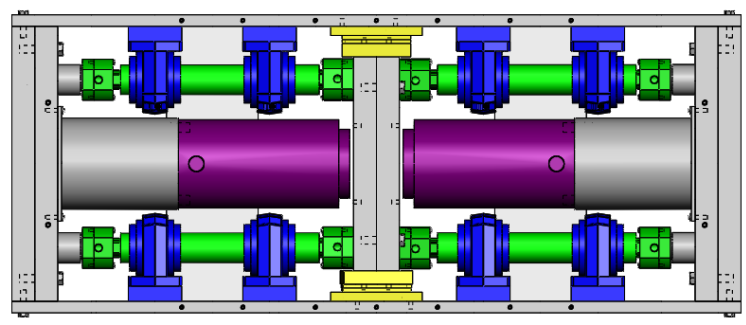

(c) University of Maryland, compression, Ni-Ti tubes, driven by hydraulic cylinders, stationary SMA, cyclic HTF, with WR, with HR, $0.05 \mathrm{~Hz}$ operating frequency 


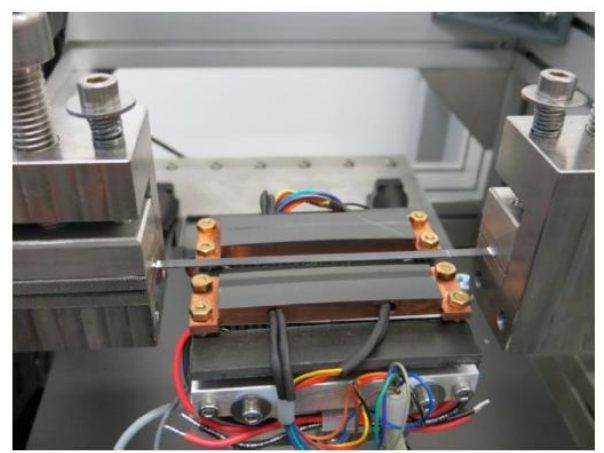

(d) Saarland University, tension, Ni-Ti plate, driven by linear motors, stationary SMA, mobile solid heat sink/source, no WR, no HR, $0.4 \mathrm{~Hz}$ operating frequency (Schmidt et al., 2014, 2015)
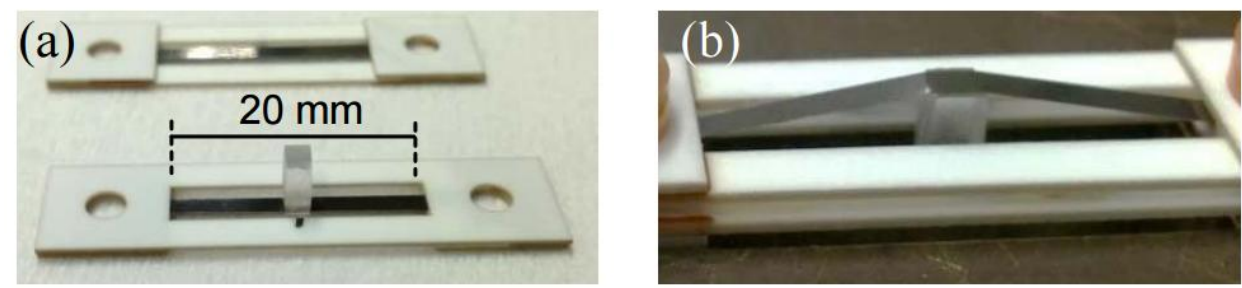

(e) Karlsruhe Institute of Technology, tension, Ni-Ti plate, driven by spindle motor, mobile SMA, steady solid-state heat sink/source, with WR, no HR, $0.66 \mathrm{~Hz}$ operating frequency (Ossmer et al., 2015)

Figure 11: Pictures of up-to-date elastocaloric cooling prototypes. 
Figure captions:

Figure 1: Illustration of the elastocaloric effect found in shape memory alloys.

Figure 2: Illustration of the typical features of an elastocaloric cooling system.

Figure 3: Graphical represent of hysteresis curves, constitutive relation and a three-dimensional figure of the phase diagram of elastocaloric materials.

Figure 4: Performance summary of elastocaloric materials.

Figure 5: Possible single stage cooling cycles based on elastocaloric effect (Qian et al., 2015b).

Figure 6: Illustration of different system heat transfer configurations.

Figure 7: Summary of a few typical heat engines using elastocaloric materials.

Figure 8: Summary of tension and compression linear driving system options for elastocaloric cooling systems.

Figure 9: Effect of varying the performance assessment indices on the elastocaloric cooling system performance.

Figure 10: HTF comparison using the heat transfer time constant and TMR as indices.

Figure 11: Pictures of up-to-date elastocaloric cooling prototypes. 
Table 1: Elastocaloric materials summary.

\begin{tabular}{|c|c|c|c|c|c|c|}
\hline \multicolumn{2}{|c|}{ Materials } & \multirow{2}{*}{$\begin{array}{l}\Delta T_{\text {ad }} \\
{\left[{ }^{\circ} \mathrm{C}\right]}\end{array}$} & \multirow{2}{*}{$\begin{array}{c}\rho \\
{\left[\mathrm{kg} / \mathrm{m}^{3}\right]}\end{array}$} & \multirow{2}{*}{$\begin{array}{c}E D \\
{\left[\mathrm{MJ} / \mathrm{m}^{3}\right]}\end{array}$} & \multirow{2}{*}{ Cons } & \multirow{2}{*}{ References } \\
\hline Composition & Category & & & & & \\
\hline $\mathrm{Ag}-\mathrm{Cd}$ & & l & l & l & & Krishnan and Brown, 1973 \\
\hline $\mathrm{Ag}-\mathrm{Zn}$ & phased & / & / & l & little knowledge & Cornelis and Wayman, 1974 \\
\hline $\mathrm{Au}-\mathrm{Cd}$ & out SMAs & / & / & / & on thermal & Lieberman et al., 1955 \\
\hline In-Tl & & / & / & I & & Basinski and Christian, 1954 \\
\hline $\mathrm{Cu}-\mathrm{Zn}$ & \multirow{7}{*}{$\begin{array}{l}\text { copper } \\
\text { SMAs }\end{array}$} & $11.3-14$ & $8,500-8,550$ & $39-49$ & \multirow{7}{*}{$\begin{array}{c}\text { brittle } \\
\text { aging } \\
\text { poor fatigue }\end{array}$} & Romero and Pelegrina, 2003 \\
\hline $\mathrm{Cu}-\mathrm{Zn}-\mathrm{Al}$ & & $11.7-19.0$ & $7,800-8,000$ & $37-64$ & & Bonnot, et al., 2008 \\
\hline $\mathrm{Cu}-\mathrm{Al}-\mathrm{Ni}$ & & 13.6 & $7,100-7,200$ & $34-44$ & & Picornell et al., 2004 \\
\hline $\mathrm{Cu}-\mathrm{Al}-\mathrm{Mn}$ & & $9-15$ & $7,100-7,500$ & $28-37$ & & Sutou et al., 2004 \\
\hline $\mathrm{Cu}-\mathrm{Al}-\mathrm{Be}$ & & $9.4-16$ & $7,000-7,300 *$ & $26-47$ & & $\begin{array}{c}\text { Manosa et al., 1993, Planes et } \\
\text { al., } 1992\end{array}$ \\
\hline $\mathrm{Cu}-\mathrm{Sn}$ & & l & / & I & & Miura et al., 1975 \\
\hline $\mathrm{Cu}-\mathrm{Au}-\mathrm{Zn}$ & & $3.9--4.9$ & $10,812 *$ & $14-18$ & & Miura et al., 1974 \\
\hline Fe-Ni-Co-Ti & & / & / & I & \multirow{4}{*}{ small latent heat } & Maki et al., 1984 \\
\hline Fe-Pd & ferrous & 2.3 & $10,729 *$ & 5.9 & & Xiao et al., 2013 \\
\hline $\mathrm{Fe}-\mathrm{Pt}$ & SMAs & 1 & / & I & & Foos et al., 1975 \\
\hline $\mathrm{Fe}-\mathrm{Rh}$ & & 5.2 & 10,111 & 24.7 & & Nikitin et al., 1992 \\
\hline $\mathrm{Ni}-\mathrm{Ti}$ & \multirow{6}{*}{$\begin{array}{c}\text { Ni-based } \\
\text { SMAs }\end{array}$} & $17-23$ & $6,400-6,500$ & $60-82$ & \multirow{6}{*}{ high cost } & Cui et al., 2012 \\
\hline $\mathrm{Ti}-\mathrm{Ni}-\mathrm{Cu}$ & & $6.1-15.5$ & 6,500 & $33-82$ & & Nam et al., 1990, Bechtold et \\
\hline Ti-Ni-Nb & & I & l & I & & Piao et al., 1992 \\
\hline Ti-Pd-Ni & & l & / & / & & Shimizu et al., 1998 \\
\hline $\mathrm{Ni}-\mathrm{Fe}-\mathrm{Ga}$ & & $10.7-11.7$ & 8,600 & $42-46$ & & Pataky et al., 2015 \\
\hline $\mathrm{Ni}-\mathrm{Fe}-\mathrm{Ga}-\mathrm{Co}$ & & $9-10$ & 8,600 & $35-40$ & & Xiao et al., 2015 \\
\hline
\end{tabular}

*: density estimated based on the alloy composition averaged pure substances density 
Table 2: Summary of different driver options for an elastocaloric cooling system.

\begin{tabular}{cccccc}
\hline Driver & Force & Displacement & Cost & Complexity & Profile \\
\hline Pneumatic & 0 & + & + & + & - \\
Hydraulic & ++ & + & - & + & ++ \\
Linear motor & - & ++ & ++ & ++ & 0 \\
Screw-jack & ++ & + & - & 0 & - \\
Piezoelectric & + & - & + & + & - \\
Crankshaft & + & 0 & - & - & + \\
\hline
\end{tabular}

Zero means acceptable for a small scale prototype but should be improved.

Minus means significant drawback

Plus means capable for large scale prototype

Double plus means better performance. 
Table 3: Key differences between the stationary SMA and mobile SMA designs.

\begin{tabular}{|c|c|c|}
\hline & Stationary SMA design & Mobile SMA design \\
\hline Heat sink/source operation & Cyclic / mobile & Stationary / steady state \\
\hline System complexity & $\begin{array}{c}\text { Need valves and pumps to } \\
\text { cycle HTF }\end{array}$ & $\begin{array}{c}\text { Need additional motor / } \\
\text { auxiliary parts to move SMA }\end{array}$ \\
\hline Friction & $\begin{array}{l}\text { Minimum friction with good } \\
\text { alignment }\end{array}$ & $\begin{array}{l}\text { Need careful design to } \\
\text { minimize friction }\end{array}$ \\
\hline Cyclic loss & $\begin{array}{l}\text { HTF dead thermal mass } \\
\text { contributes to significant loss }\end{array}$ & Minimum cyclic loss \\
\hline Heat recovery feature & $\begin{array}{l}\text { Capable to have HR or active } \\
\text { regeneration design to reduce } \\
\text { cyclic loss impact }\end{array}$ & HR is very difficult to apply \\
\hline Work recovery feature & Capable & Capable with friction loss \\
\hline Frequency & Low & High \\
\hline
\end{tabular}


Table 4: Summary of key issues to be addressed for a successful prototype.

\begin{tabular}{|c|c|}
\hline Materials & $\begin{array}{ll}\text { - } & \text { Low hysteresis } \\
\text { - } & \text { High latent heat } \\
\text { - } & \text { Long fatigue life } \\
\text { - } & \text { Small transformation stress } \\
\text { - } & \text { Low cost }\end{array}$ \\
\hline Driver & $\begin{array}{ll}\text { - } & \text { Low cost } \\
\text { - } & \text { Compactness } \\
\text { - } & \text { Moderate precision } \\
\text { - } & \text { Large force and small displacement } \\
\end{array}$ \\
\hline Material structure design & $\begin{array}{ll}\text { - } & \text { Minimum friction } \\
\text { - } & \text { Uniform phase change }(\Phi) \\
\text { - } & \text { Large heat transfer surface to volume ratio }\end{array}$ \\
\hline System structure design & $\begin{array}{l}\text { - Compact design capable to handle a large force } \\
\text { - } \quad \text { Light weight } \\
\text { - } \text { High heat transfer surface to volume ratio }\end{array}$ \\
\hline Heat transfer design & $\begin{array}{ll}\text { - } & \text { Compactness } \\
\text { - } & \text { Small heat transfer time constant } \tau \\
\text { - } & \text { High efficient heat recovery/regeneration }\left(T M R_{\mathrm{HR}}\right) \\
\text { - } & \text { Minimum pressure drop } \\
\text { - } & \text { Minimum parasitic parts and loss } \\
\text { - } & \text { Optimum fluid thermal mass }(T M R)\end{array}$ \\
\hline
\end{tabular}

